\title{
The effect of maternal dietary fat content and omega- 6 to omega-3 ratio on offspring growth and hepatic gene expression in the rat
}

\begin{tabular}{|r|l|}
\hline Journal: & British Journal of Nutrition \\
\hline Manuscript ID & BJN-RA-19-0728.R1 \\
\hline Manuscript Type: & Research Article \\
\hline Author: & 27-Jan-2020 \\
\hline Complete List of Authors: & $\begin{array}{l}\text { Draycott, Sally; University of Nottingham, Biosciences; The University of } \\
\text { Adelaide, School of Agriculture, Food and Wine } \\
\text { George, Grace; University of Nottingham, Biosciences } \\
\text { Elmes, Matthew; University of Nottingham, Biosciences } \\
\text { Muhlhausler, Beverly; University of Adelaide, Food and Nutrition } \\
\text { Research Group; Commonwealth Scientific and Industrial Research } \\
\text { Organisation, Nutrition and Health Research } \\
\text { Langley-Evans, Simon; University of Nottingham, Biosciences }\end{array}$ \\
\hline Keywords: & Maternal nutrition, Omega, Pregnancy, Growth restriction \\
\hline Subject Category: & Molecular Nutrition \\
\hline & \\
\hline
\end{tabular}


1 The effect of maternal dietary fat content and omega-6 to omega-3 ratio on offspring 2 growth and hepatic gene expression in the rat

3 Sally A V Draycott ${ }^{1,2}$, Grace George, Matthew J Elmes ${ }^{1}$, Beverly S Muhlhausler ${ }^{2,3}$ and

4 Simon C Langley-Evans ${ }^{1 *}$

$5{ }^{1}$ School of Biosciences, University of Nottingham, Sutton Bonington Campus,

6 Loughborough, UK

$7 \quad{ }^{2}$ Food and Nutrition Research Group, Department of Food and Wine Science, School of

8 Agriculture Food and Wine, University of Adelaide, Adelaide, Australia

$9{ }^{3}$ Commonwealth Scientific and Industrial Research Organisation, Adelaide, Australia 10

$11 *$ Corresponding author

12 Simon Langley-Evans

13 Sutton Bonington Campus

14 Sutton Bonington

15 Leicestershire

16 LE12 5RD

17 UK

18 Simon.Langley-evans@,nottingham.ac.uk

19

20 Short title: Maternal diet, offspring gene expression.

21 Key words: Maternal nutrition, omega-6, omega-3, pregnancy, growth restriction 


\section{Abstract}

24 Omega-6 fatty acids have been shown to exert pro-adipogenic effects whereas omega-3 fatty 25 acids_appear to-work in opposition. Increasing intakes of LA (linoleic acid; omega-6) vs 26 ALA (alpha-linolenic acid; omega-3) in Western diets has led to the hypothesis that 27 consumption of this diet during pregnancy may be contributing to adverse offspring health.

28 This study investigated the effects of feeding a maternal dietary LA:ALA ratio similar to that 29 of the Western diet (9:1) compared to a proposed 'ideal' ratio $(\sim 1: 1.5)$, at two total fat levels $30 \quad(18 \%$ vs $36 \%$ fat $\mathrm{w} / \mathrm{w})$, on growth and fat depositionlipogenic gene expression in the 31 offspring. Female Wistar rats were assigned to one of the four experimental groups 32 throughout gestation and lactation. Offspring were culled at 1 and 2 weeks of age for blood 33 and tissue sample collection. Offspring of dams consuming a high-36\% fat diet were $20 \%$ 34 lighter than those exposed to a tow $18 \%$ fat $\operatorname{diet}(\mathrm{P}<0.001)$. Male, but not female, liver weight 35 at 1 week was $\sim 13 \%$ heavier, and had increased glycogen $(\mathrm{P}<0.05)$, in offspring exposed to high LA $(\mathrm{P}<0.01)$. Hepatic expression of lipogenic genes suggested an increase in lipogenesis

37 in male offspring exposed to a high $\underline{36 \%}$ fat maternal diet and in female offspring exposed to 38 a low LA diet, via increases in the expression of Fasn and Srebfl. Sexually dimorphic 39 responses to altered maternal diet appeared to persist until two weeks-of-age. In conclusion, 40 whilst maternal total fat content predominantly affected offspring growth, fatty acid ratio and 41 total fat content had sexually dimorphic effects on offspring liver morphology weight and composition. 


\section{Introduction}

44 Accumulating evidence suggests that the nutritional environment experienced by an individual during fetal and early infant development has long-lasting impacts on their metabolic health ${ }^{(1)}$. In the context of the global epidemic of obesity and nutritional excess, there has been considerable interest in determining the effects of maternal overnutrition on the metabolic health of the offspring. The majority of these studies have utilised animal models and have consistently reported that maternal high-fat feeding during pregnancy has detrimental effects on the metabolic health of both the mother and her offspring ${ }^{(2,3)}$. As a result, excess maternal fat consumption has been implicated as a key contributor to metabolic programming of longterm health and disease risk.

There is increasing evidence, however, that the impact of a high-fat diet on the metabolic health of the offspring depends not only on the amount of fat in the diet, but also on the fatty acid composition ${ }^{(4,5)}$. There has been particular interest in the role of two classes of polyunsaturated fatty acids (PUFA), due to the substantive increase in the amounts of omega6 PUFA, predominately linoleic acid (LA), being consumed in the diets of many Western countries over the past few decades ${ }^{(6,7)}$. This increase in the intake of LA intakes has not been accompanied by substantial changes in the consumption of omega-3 PUFA such as alpha-linolenic acid (ALA) and has therefore resulted in increases in the ratio of omega6:omega-3 PUFA consumed in the diets of many Western countries ${ }^{(6,8)}$.

The increasing dominance of omega-6 over omega-3 PUFA in modern Western diets has considerable biological significance, since the omega- 6 and omega-3 fatty acid families utilise the same enzymes for production of longer chain bioactive derivatives such as arachidonic acid (AA; omega-6), eicosapentaenoic acid (EPA; omega-3), docosapentaenoic acid (DPA; omega-3) and docosahexaenoic acid (DHA; omega-3), and also compete for incorporation into cell membranes. As a result, excess consumption of LA leads to a decrease in the production and incorporation of omega-3 fatty acids through simple substrate competition, and this effect is exacerbated when total dietary PUFA is high ${ }^{(9,10)}$. The omega3 and omega-6 long-chain polyunsaturated fatty acids (LCPUFA) derivatives also have opposing physiological actions, with those from the omega-3 family predominately exhibiting anti-inflammatory properties (for example via the suppression of the proinflammatory transcription factor nuclear factor kappa B and activation of the antiinflammatory transcription factor peroxisome proliferator activated receptor $\left.\gamma^{(11)}\right)$ and those 
from the omega- 6 family exhibiting more pro-inflammatory and pro-adipogenic properties (12). This has led to the hypothesis that the increasing ratio of omega- 6 to omega- 3 fatty acids in modern Western diets may have negative effects on conditions characterised by low-grade inflammation, including obesity and the metabolic syndrome, and may potentially be contributing to an intergenerational cycle of obesity ${ }^{(8)}$.

Data from observational studies in humans and animal models provide supporting evidence that suggests high intakes of omega-6 PUFA during pregnancy could have negative effects on metabolic health of the progeny ${ }^{(13,14,15)}$. However, the results of these studies have not been consistent. The results of pre-clinical studies are also limited by the use of diets with much higher omega-6:omega-3 PUFA ratios and/or absolute PUFA contents than those encountered in typical human diets. Furthermore, offspring often continue to have access to the same diet as their mother so that any effects observed cannot be clearly attributed to dietary fatty acid exposure during the gestation and lactation periods ${ }^{(16,17,18)}$. The aim of this study, therefore, was to investigate the effects of feeding a maternal dietary LA:ALA ratio similar to that of the Western diet $(9: 1)^{(6)}$, compared to a proposed 'ideal' ratio of $1: 1.5^{(19,20)}$ on growth and

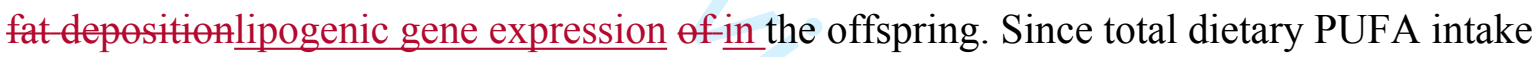
also influences PUFA metabolism ${ }^{(9,10)}$, we also investigated the effect of feeding each dietary fat ratio at either $18 \%$ fat $\mathrm{w} / \mathrm{w}$ (in line with dietary recommendations ${ }^{(21)}$ ) or at a higher fat level of $36 \%$ fat w/w. A rat model was utilised to achieve the study objectives by allowing for tight control of dietary manipulation as well as invasive end points.

\section{Materials and Methods}

Animals

All animal procedures were performed in accordance with the Animals (Scientific Procedures) Act 1986 under Home Office licence and were approved by the Animal Ethics Committee of the University of Nottingham, UK. Virgin female Wistar rats $(n=30 ; 75-100 g$; Charles River, UK) were housed on wood shavings in individually ventilated cages under a 12 hour light/12 hour dark cycle at a temperature of $20-22^{\circ} \mathrm{C}$ and had ad libitum access to food and water throughout the experiment. Female rats were allowed to acclimatise to the unit for 1-2 weeks, during which time they were fed standard laboratory chow (2018 Teklad Global 18\% Protein Rodent Diet, Harlan Laboratories, UK). After acclimatisation, a tail vein blood sample was taken from each animal for the determination of fatty acid status. The rats were then randomly 
assigned to one of 4 dietary groups (details provided below). Animals were maintained on their allocated diet for a four week 'pre-feeding' period, after which they were mated. Conception was confirmed by the presence of a semen plug and this was recorded as day 0 of pregnancy. Animals were housed in individual cages and remained on their respective diets throughout pregnancy and lactation.

Litters were standardised to 8 pups within 24 hours of birth (4 males and 4 females, where possible). At 1 and 2 weeks of age, one randomly selected male and one randomly selected female from each litter were culled via cervical dislocation and exsanguination for blood and tissue collection. At 3 weeks of age, the remaining offspring were weaned and dams were then euthanised by $\mathrm{CO}_{2}$ asphyxiation and cervical dislocation for collection of maternal blood and tissues. All dams were weighed and had feed intake measured daily throughout the experiment and offspring bodyweight was measured weekly.

Diets

Diets were designed to provide either a high (9:1, high LA) or low (1:1.5, low LA) ratio of LA $\underline{\text { (cis/cis isomer) }}$ to ALA, achieved by altering the amounts of flaxseed and sunflower oil included in the fat component of the feed. The levels of saturated and monounsaturated fatty acids were comparable in all diets, achieved by adjusting the amounts of coconut (saturated fat source) and macadamia (monounsaturated fat source) oils in the diets. For each level of LA, diets were developed to containing either $18 \%$ fat $(w / w)$, in line with government recommendations ${ }^{(21)}$ or $36 \%$ fat $(\mathrm{w} / \mathrm{w})$ to highlight any additive effects vs $63.5 \%$ of dietary energy respectively). This resulted in four experimental diets ( $\mathrm{n}=6-9$ per dietary group); high LA (18\% fat), high LA (36\% fat), low LA (18\% fat) and low LA (36\% fat). The list of ingredients and final fatty acid composition of the four experimental diets have been reported previously ${ }^{(5)}$.

\section{Blood sample and tissue collection}

135 Blood samples were collected from dams prior to the start of the experiment and after the 4 week 'feed-in' period (tail vein sample) and at the end of lactation (via cardiac puncture following $\mathrm{CO}_{2}$ asphyxiation and cervical dislocation). Truncal blood samples were also collected from one randomly selected male and one randomly selected female at 1 and 2 weeks of age. In all cases, samples of whole blood $(\sim 30 \mu l)$ from non-fasted animals were spotted onto PUFAcoat ${ }^{\mathrm{TM}}$ dried blood spot (DBS) collection paper ${ }^{(22)}$, allowed to dry at room temperature 
141 and stored at $-20^{\circ} \mathrm{C}$ for subsequent fatty acid analysis. Maternal tissues were weighed and 142 samples of whole liver, retroperitoneal and gonadal adipose tissues collected. Offspring body and organ weights were measured and whole liver samples were collected from one randomly selected male and female pup at both time points. At 2 weeks of age, samples of gonadal and retroperitoneal fat were also collected from one male and one female pup per litter. All tissue samples were snap-frozen in liquid nitrogen and stored at $-80^{\circ} \mathrm{C}$ until determination of gene expression by quantitative reverse transcriptase PCR (qRT-PCR).

\section{Fatty acid methylation and analysis}

Fatty acid composition in maternal and fetal blood was determined as previously described (22). Briefly, whole DBS samples were directly transesterified with $2 \mathrm{ml}$ of $1 \% \mathrm{H}_{2} \mathrm{SO}_{4}$ in methanol and the fatty acid methyl esters (FAME) were extracted with heptane. Samples were separated and analysed by a Hewlett-Packard 6890 gas chromatograph (GC) equipped with a capillary column (30m x $0.25 \mathrm{~mm})$ coated with $70 \%$ cyanopropyl polysilphenylene-siloxane (BPX-70; $0.25 \mu \mathrm{m}$ film thickness) which was fitted with a flame ionization detector (FID). FAMEs were identified in unknown samples based on the comparison of retention times with an external lipid standard (Standard 463, Nu-check prep Inc., MN, USA) using Agilent Chemstation software (Agilent Technologies Australia Pty Ltd). Individual fatty acid content was calculated based on peak area and response factors normalised to total fatty acid content and expressed as a percentage of total fatty acids.

Isolation of RNA and cDNA synthesis and quantitative reverse transcription real-time PCR $(q R T-P C R)$

RNA was isolated from crushed snap-frozen samples of $\sim 25 \mathrm{mg}$ of liver using the Roche High Pure Tissue kit (Roche Diagnostics Ltd., UK). Adipose RNA was extracted, after homogenisation of $\sim 100 \mathrm{mg}$ of tissue with MagNA lyser green beads and instrument (Roche Diagnostics Ltd.), using the RNeasy Mini Kit (QIAGEN Ltd., UK). RNA concentration was determined using a Nanodrop 2000 (Thermo Scientific) and RNA quality was evaluated by agarose gel electrophoresis. cDNA was synthesised using a RevertAid ${ }^{\mathrm{TM}}$ reverse transcriptase kit (Thermo Fisher Scientific, UK) with random hexamer primers.

Lipogenic pathway and adipokine target genes were chosen based on previous data from our laboratory that indicated that these genes were sensitive to changes in the maternal diet ${ }^{(23)}$ and included; peroxisome proliferator-activated receptor gamma (Pparg), sterol regulatory 
element-binding protein (variant 1c; Srebfl), fatty acid synthase (Fasn), lipoprotein lipase ( $L p l$ ) and leptin (Lep), with $\beta$-actin (Actb) as the housekeeper. Primer efficiency ranged from $85 \%$ $108 \%$ and sequences have previously been published elsewhere ${ }^{(5)}$. Adipocyte and hepatic gene expression was quantified using SYBR Green (Roche Diagnostics) in a Light-Cycler 480 (Roche Diagnostics). Samples were analysed against a standard curve of a serially diluted cDNA pool to produce quantitative data and expression was normalised to the housekeeping gene using LightCycler ${ }^{\circledR} 480$ software (version 1.5.1) as previously described ${ }^{(24)}$. The expression of the housekeeper gene was not different between treatment groups.

\section{Determination of liver DNA, protein and glycogen content}

For determination of DNA and protein content of liver samples, approximately $100 \mathrm{mg}$ of frozen crushed sample was added to $1 \mathrm{ml}$ of $0.05 \mathrm{M}$ trisodium citrate buffer. Samples were homogenised and centrifuged at $2500 \mathrm{rpm}$ for 10 minutes at $4{ }^{\circ} \mathrm{C}$. Supernatant was used for further analyses. DNA concentration ( $\mathrm{ug} / \mathrm{ml}$ ) was measured using a Hoechst fluorimetric method and protein content (ug/well), modified for a 96 well plate format, was measured as described by Lowry et al. ${ }^{(25)}$. Measurements were normalised to the exact amount of tissue used for measurements. Liver glycogen was measured using the Colorimetric Glycogen Assay Kit II (Abcam Ltd.) according to manufacturer's instructions.

\section{Statistical analysis}

Data are presented as mean \pm SEM. Data were analysed using the Statistical Package for Social Sciences (Version 24, SPSS Inc.). The effect of maternal dietary fatty acid ratio and maternal dietary fat content on maternal dependent variables was assessed using a two-way ANOVA, with dietary LA:ALA ratio and dietary fat content as factors and dams were used as the unit of analysis. Where longitudinal data were analysed, as with maternal feed, protein and energy intakes, the impact of maternal dietary LA:ALA ratio and maternal dietary fat content was analysed using a two-way repeated-measures ANOVA. Offspring data were analysed using a two-way ANOVA, with maternal dietary LA:ALA ratio and fat content as factors; where there was no overall effect of sex, male and female offspring data were combined. Where data were not normally distributed, analyses were performed on $\log 10$ transformed data. A value of $\mathrm{P}<0.05$ was considered to be statistically significant. 


\section{Results}

\section{Maternal dietary intakes}

209 There were no differences in feed intake of dams between treatment groups before or during 210 pregnancy. During lactation, dams receiving the $36 \%$ fat diets had a lower average daily feed 211 intake than those receiving the $18 \%$ fat diets, irrespective of dietary LA:ALA ratio $(\mathrm{P}<0.001$;

212 Fig 1a). Energy intake was similar between groups throughout the experiment (Fig. 1b). Protein 213 intake prior to and during pregnancy was affected by both dietary LA:ALA ratio and fat content 214 ( $<<0.05$; Fig. 1c), however, these effects were small and inconsistent. During lactation, protein 215 intake was affected by dietary fat content only $(\mathrm{P}<0.001$; Fig. 1c), such that mothers receiving 216 high-36\% fat diets $(36 \%$ fat $)$-consumed $24 \%$ less protein on average compared to those 217 consuming lower $(18 \%)$ fat diets, irrespective of dietary LA:ALA ratio. As expected, all dams consumed more food, energy and protein during lactation than before and during pregnancy regardless of dietary group $(\mathrm{P}<0.001)$.

\section{Maternal fatty acid profile}

There were no differences in the proportions of either saturated fatty acids (SFA), monounsaturated fatty acids (MUFA), omega-6 (Fig. 2a) or omega-3 PUFA (Fig. 2b) in whole blood samples collected from the dams prior to the commencement of dietary intervention. After 4 weeks on their respective diets, the blood fatty acid profiles were significantly different between treatment groups and largely reflected the composition of the experimental diets. Thus, dams fed on high LA diets had higher proportions of LA (1.2 fold) and AA (1.4 fold) compared to those consuming a low LA $\operatorname{diet}(\mathrm{P}<0.001$; Fig. $2 \mathrm{c})$. Conversely, dams fed the low LA diets had a 5.5 fold higher proportion of ALA and an 8.5 fold higher proportion of EPA compared to those consuming a high LA diet $(\mathrm{P}<0.001$; Fig. 2D). These changes were independent of the total fat content of the diet. DPA and DHA levels after the 4 week prefeeding period were influenced by both dietary LA:ALA ratio and total fat content. Thus, the relative proportions of DPA were higher in dams fed the low LA compared to high LA diets $(\mathrm{P}<0.001)$, and marginally higher in dams consuming the $18 \%$ vs $36 \%$ fat $\operatorname{diets}(\mathrm{P}<0.05)$. DHA proportions were also higher in the low LA group $(\mathrm{P}<0.001)$ but, unlike DPA, were modestly but significantly higher in dams consuming the $36 \%$ fat vs $18 \%$ fat diets $(\mathrm{P}<0.05$; Fig. $2 \mathrm{D})$. Total blood MUFA proportions were higher (1.3-fold) in dams consuming the low LA diet, irrespective of dietary fat content $(\mathrm{P}<0.001$; Fig. $2 \mathrm{C})$. 
240 The blood fatty acid profile of the dams at the end of lactation, after a further 6 weeks on their respective experimental diets, were similar to those observed after the first 4 weeks of dietary intervention. A notable difference, however, was that at this time point, relative proportions of DHA, as a percentage of total lipids, were not different between dietary groups (Fig. 2F). LA (1.5-fold), AA (1.8-fold) and total omega-6 (1.5-fold) were all higher in dams consuming a high LA diet irrespective of dietary fat content ( $\mathrm{P}<0.001$; Fig. 2E). Conversely, total omega-3 levels were 3-fold higher in dams consuming a low LA diet, irrespective of dietary fat content $(\mathrm{P}<0.001)$. The proportions of ALA were also higher in the groups consuming the low LA diets and in rats consuming the $36 \%$ vs $18 \%$ fat diets in the low LA group only $(\mathrm{P}<0.05$; Fig $2 \mathrm{~F})$. DPA proportions were higher in the groups consuming the low LA diets, however, unlike ALA, DPA proportions were lower, rather than higher, in dams consuming the $36 \%$ fat diets in the low LA group only $(\mathrm{P}<0.001$; Fig. $2 \mathrm{~F})$. EPA proportions were higher in groups consuming a low LA diet compared to those consuming a high LA diet $(\mathrm{P}<0.001$; Fig. $2 \mathrm{~F})$. EPA proportions were also affected by total dietary fat content, and were lower in dams consuming a high- $\underline{36 \%}$ fat $(36 \%$ fat $)$ diet compared to an torer $(18 \%$ fat $) \operatorname{diet}(\mathrm{P}<0.001$; Fig. $2 \mathrm{~F})$. Maternal blood total MUFA levels at the end of lactation were 1.4-fold higher in the dams consuming a low LA diet irrespective of dietary fat content $(\mathrm{P}<0.001$; Fig. $2 \mathrm{E})$.

\section{Maternal weight, body composition and gene expression}

There were no significant differences in dam bodyweight between dietary groups prior to the commencement of the dietary intervention or at any time during the experiment (data not shown). Dams consuming the $36 \%$ fat diets had heavier lungs relative to bodyweight at the end of lactation compared to those consuming the $18 \%$ fat diets, independent of the LA:ALA ratio $(\mathrm{P}<0.05)$. There were no differences in the relative weight of the heart, liver, brain, kidney, gonadal or retroperitoneal fat pads between experimental groups (Table 1).

Analysis of mRNA expression of lipogenic genes indicated that hepatic (3-fold) and gonadal fat (7-fold) expression of Fasn was higher in dams consuming an 18\% fat diet, compared to those on a $36 \%$ fat diet, irrespective of dietary fatty acid ratio $(\mathrm{P}<0.01)$. The mRNA expression of Lpl, Pparg and Srebfl was not, however, affected by either dietary fat content or ratio in either hepatic or gonadal fat tissues (Table 1). Expression of leptin mRNA in gonadal adipose tissue was not significantly different between treatment groups. 
274 There were no differences between dietary groups in terms of litter size or sex ratio of pups

275 (Table 2). Birth weight was lower in offspring of dams fed a $36 \%$ fat vs $18 \%$ fat diets, 276 independent of the dietary LA:ALA ratio (Table 2). The lower body weight in offspring of 277 dams fed the $36 \%$ fat diet persisted during the sucking period such that offspring of dams fed 278 the $36 \%$ fat diets remained lighter than offspring of dams fed on $18 \%$ fat diets at both 1 and 2 weeks of age; again this was independent of dietary LA:ALA ratio $(\mathrm{P}<0.001$; Table 3$)$.

\section{Offspring fatty acid profile}

282

283

284

285

286

287

288

289

290

291

292

293

294

295

296

297

298

299

300

301

302

303

304

305

At 1 week of age, proportions of AA (2.1 fold) were lower in the offspring of the low LA compared to high LA dams ( $\mathrm{P}<0.001)$, and in offspring of dams consuming the $36 \%$ fat vs $18 \%$ fat diets (1.4 fold; $\mathrm{P}<0.001$; Fig. 3A). Blood ALA proportions were 5.9 fold higher in offspring of dams in the low LA groups compared to high LA groups ( $\mathrm{P}<0.001$; Fig. 3B). Offspring EPA and DPA proportions were also higher in the low LA group compared to the high LA group. Blood EPA was also influenced by total dietary fat content, but only in offspring of dams fed the low LA diet, in which EPA levels were lower in offspring of dams fed the $36 \%$ fat diets compared to the $18 \%$ fat diets (EPA, $\mathrm{P}<0.001$; DPA, $\mathrm{P}<0.01$; Fig. $3 \mathrm{~B}$ ). DHA proportions were not different between groups at 1 week of age (Fig. 3B). MUFA proportions were higher (1.2fold) in offspring of dams in the low LA groups $(\mathrm{P}<0.001)$, consistent with the pattern in maternal blood. However, unlike maternal MUFA, offspring MUFA levels were also affected by maternal dietary fat content and were 1.2-fold higher in offspring of dams fed the $36 \%$ fat vs $18 \%$ fat diets $(\mathrm{P}<0.001$; Fig. 3A). At 1 week of age offspring of dams in the $36 \%$ fat diet groups also had lower blood proportions of SFA, irrespective of LA:ALA ratio of the maternal $\operatorname{diet}(\mathrm{P}<0.01$; Fig. 3A).

The fatty acid profiles of the offspring at 2 weeks of age were similar to those observed at 1 week. Thus, blood AA (1.9 fold) and total omega-6 (1.6 fold) proportions were lower (Fig. 3C) and ALA (6.3 fold), EPA (4.7 fold), DPA (2.4 fold) and total omega-3 PUFA (3-fold) proportions (Fig. 3D) were higher in offspring of dams in the low LA group compared to high LA groups, irrespective of maternal dietary fat content $(\mathrm{P}<0.001)$. Proportions of LA were higher in offspring of dams fed the $36 \%$ fat diets compared to those fed $18 \%$ fat diets in the high LA group only ( $\mathrm{P}<0.05$; Fig $3 \mathrm{C}$ ), while EPA and DPA proportions were lower in the $36 \%$ compared to the $18 \%$ fat diet groups, independent of the dietary LA:ALA ratio $(\mathrm{P}<0.001$; Fig. 3D). Unlike findings at 1 week of age, the DHA levels in 2 week old offspring of dams consuming a $36 \%$ fat diet were lower $(\mathrm{P}<0.05)$ when compared to $18 \%$ fat groups, irrespective 
308 of maternal dietary fatty acid ratio. As at 1 week, SFA proportions were lower (1.2-fold) in 309 offspring of dams fed a high- $36 \%$ fat $(36 \%)$ diet, independent of the LA:ALA ratio $(\mathrm{P}<0.001)$. 310 MUFA proportions were 1.2 fold higher in offspring of dams fed the low LA diets, and 1.2 311 fold higher in offspring of dams who consumed a $36 \%$ fat vs $18 \% \operatorname{diet}(\mathrm{P}<0.001$; Fig. $3 \mathrm{C})$.

\section{Offspring organ weight and liver composition}

314 At 1 week of age, heart weight relative to bodyweight was higher in female offspring of dams 315 receiving a high (36\%) fat diet compared to the $18 \%$ fat diet, independent of the dietary 316 LA:ALA ratio $(\mathrm{P}<0.05)$. There were no differences in the relative weight of lung or kidney at 3171 week of age and no differences in the relative weight of the heart, lung, liver, gonadal or 318 retroperitoneal fat pads in the offspring at 2 weeks of age between treatment groups in either 319 male or female offspring (Table 3).

Liver weight at 1 week appeared to be influenced by the LA:ALA ratio of the diet to a greater extent than total fat level, at least in males. Thus, male offspring of dams consuming the high LA diets had increased liver weights compared to offspring of dams receiving a low LA diet $(\mathrm{P}<0.01)$, irrespective of total dietary fat content. The glycogen content of the livers was also higher in male offspring of dams consuming the high LA diets at 1 week of age $(\mathrm{P}<0.05)$. No effect of maternal diet on offspring liver protein or DNA concentration was observed (Table 4). These differences were not present in females at 1 week of age and no differences in glycogen content were observed at two weeks of age in male offspring. DNA concentration in females at two weeks of age was marginally increased (1.1-fold) in offspring exposed to a high$\underline{36 \%}$ fat diet, irrespective of maternal dietary fatty acid ratio $(\mathrm{P}<0.05)$.

\section{Hepatic gene expression}

333 At 1 week of age, hepatic Fasn expression was influenced by maternal dietary intervention in a sex specific manner. Thus, in males, Fasn expression was higher in offspring of dams consuming a high-36\% fat $(36 \%)$ diet irrespective of maternal LA:ALA ratio $(\mathrm{P}<0.05)$. In female offspring, however, Fasn expression was higher in offspring of dams consuming a low LA diet, independent of dietary fat content $(\mathrm{P}<0.05)$. Hepatic $\mathrm{Lpl}$ mRNA expression in male offspring at 1 week of age was also influenced by maternal dietary fat content, with higher expression in offspring of dams consuming a $36 \%$ fat diet vs a low $18 \%$ fat $\operatorname{diet}(\mathrm{P}<0.05)$. In female offspring, hepatic Srebf expression, similar to that of Fasn, was higher in offspring of dams consuming a low LA diet at 1 and 2 weeks of age $(\mathrm{P}<0.01)$. Female hepatic expression 
of Pparg was lower in offspring of dams consuming a low LA diet at 2 weeks of age $(\mathrm{P}<0.05)$.

343 There were no differences in the expression of Fasn or $\mathrm{LPl}$ in female offspring, or expression

344 of any hepatic genes in male offspring at this time point (Table 3 ).

\section{Discussion}

This study has demonstrated that altering the fat content and/or LA:ALA ratio of the maternal diet during pregnancy and lactation resulted in significant alteration in the circulating fatty acid profile of dams in the absence of any significant effects on maternal bodyweight or body composition. Exposure to a high- $\underline{36 \%}$ fat diet during gestation and lactation was, however, associated with lower offspring bodyweight from birth, which persisted to 2 weeks of age. This suggests that increased dietary fat intake during pregnancy and lactation can compromise growth of the progeny, irrespective of the type of fat consumed. In addition, alterations in the fat content and/or composition of the maternal diet had transient effects on offspring body composition and hepatic gene expression, effects which were also sex-specific.

Maternal fatty acid profiles after 4 weeks on the experimental diets largely reflected dietary composition, confirming that the dietary intervention had the desired effect on maternal circulating fatty acid composition. These changes persisted after a further 6 weeks of exposure to the diets and, as expected, the dietary LA:ALA ratio had a greater impact on the maternal blood omega- 6 and omega-3 status than total dietary fat content. Consistent with previous studies $(5,9,26,27)$, decreasing the dietary LA:ALA ratio resulted in substantial increases in relative maternal ALA and EPA levels but only a very modest increase in DHA proportions after a 4-week exposure, and no difference compared to the higher LA:ALA ratio after 10 weeks. Interestingly, and independent of dietary LA:ALA ratio, dams appeared to be more efficient at converting DPA to DHA when total dietary fat load was higher. One possibility is could be that this is simply a result of the higher amount of substrate (i.e. ALA) available for conversion to the longer chain derivatives such as DPA and DHA in diets containing higher total fat levels. This effect did not, however, persist after a further 6 weeks of dietary exposure, at which point EPA and DPA were lower in dams consuming a low LA 36\% fat diet compared to a low LA $18 \%$ fat diet. This may be a result of saturation of the PUFA metabolic pathway when total fat, and therefore PUFA, levels were higher ${ }^{(10,28)}$. This apparent decrease in capacity to convert ALA through to EPA and DHA during consumption of a high- $\underline{36 \%}$ fat diet coincides with the decreased protein intake observed in these groups. It is possible that the lower consumption of protein in rats fed on the $36 \%$ fat diets may have contributed to reduced 
conversion of ALA, since previous studies have shown reduced desaturase, particularly $\Delta 6$ desaturase, expression in the mammary gland ${ }^{(29)}$ and liver ${ }^{(30)}$ of rats exposed to a low protein diet. Maternal whole blood MUFA proportions appeared to be influenced by dietary LA:ALA ratio, however, this is most likely a result of the slightly higher MUFA content of the low LA diets.

Offspring fatty acid profiles at 1 and 2 weeks of age largely reflected maternal profiles with maternal dietary LA:ALA ratio exhibiting the strongest effect on offspring circulating fatty acid proportions. However, the total fat content of the maternal diet appeared to have a greater influence on the blood fatty acid composition of the offspring thanas opposed to that observed in the dams. Of particular interest was the finding that the proportion of both EPA and DPA in offspring at 1 week of age were higher in the low LA (18\% fat) vs the low LA ( $36 \%$ fat) group, and that this effect persisted at 2 weeks of age despite ALA levels being increased in the low LA (36\% fat) group at this time point. DHA was not different between groups at 1 week of age but was lower in offspring exposed to a high-36\% fat diet at 2 weeks of age. As with the maternal fatty acid profiles, this again may be a result of saturation of the PUFA metabolic pathway at higher total PUFA intakes, and is in line with findings from numerous studies, both human and animal, that indicate that simply increasing the quantity of substrate, i.e. ALA, is not an effective strategy for increasing concentrations of its long-chain derivatives, in particular

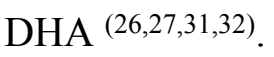

The total dietary fat content of the maternal diet also had an influence on the proportion of SFA in the offspring, such that offspring of dams consuming high- $36 \%$ fat diets exhibited lower SFA proportions than offspring of dams consuming the lower $18 \%$ fat diets. Unlike the fetus, where fatty acid composition is largely related to maternal dietary intake, during suckling, offspring fatty acid composition is largely determined by the composition of the milk, which may not fully reflect maternal fatty acid intakes. In a study by Mohammad et al. (33), for example, women consuming diets with a higher total fat content ( $55 \%$ en vs. $25 \%$ en) exhibited reduced SFA concentrations (C6:0-C14:0) in breast milk but not in maternal plasma. While milk composition was not assessed in the current study, this raises the possibility that SFA content of the milk may have been lower in those dams consuming the $36 \%$ fat diets, which could in turn explain the lower SFA status of the offspring. Alternatively, it may be that increasing the fat content of the diets resulted in an increased conversion of SFA to MUFA, since high-fat feeding has been associated with increased expression of the enzyme responsible 
410 for conversion of SFA to MUFA, stearoyl-CoA desaturase 1 (SCD-1) ${ }^{(34)}$ and could therefore 411 be the reason for the observed effect of fat content on offspring MUFA levels in this study. It 412 is important to note, however, that circulating fatty acid profiles are a product of both dietary 413 fatty acid intake as well as tissue fatty acid production and release. Whilst the collection of 414 blood samples from animals in the fed state suggests that the dietary fraction of fatty acids would provide a greater contribution to the fatty acid profile of both dams and offspring, the influence of hepatic synthesis of fatty acids should not be overlooked as a contributor to the observed differences.

419 Despite significant shifts in maternal fatty acid profiles and increased fat content of the $36 \%$ 420 fat diets, we saw no differences in maternal bodyweight or fat deposition. This is consistent with our previous study ${ }^{(5)}$ and is likely a result of the reduced feed intakes of the dams to compensate for the increased energy density of the higher fat diets, a phenomenon consistently seen with dietary intervention trials using rodents ${ }^{(35)}$. Despite the lack of an effect on maternal weight gain and fat deposition, bodyweight was reduced in offspring of dams receiving a high$\underline{36 \%}$ fat $(36 \%$ fat $)$ diet, irrespective of maternal dietary LA:ALA ratio. This phenotype was consistent across sexes and persisted from birth to 2 weeks of age. Variable results have been reported in this regard with some studies reporting no effects ${ }^{(36,37,38)}$ or increased weight ${ }^{(39)}$. This finding was, however, consistent with many other studies that reported decreased fetal ${ }^{(40,41)}$, birth ${ }^{(42)}$ and weaning weight ${ }^{(43)}$ in offspring of dams exposed to a high- $36 \%$ fat diet during gestation and lactation periods. The differential effects of different high $\underline{36 \%}$ fat diets on offspring growth is likely due to differences in composition of the diet as well as periods of exposure between studies ${ }^{(3)}$. In those studies that have reported lower offspring weights in offspring fed a high-fat diet, lower protein intakes in dams consuming a high-fat diet have been cited as a likely contributing factor. Further to this, protein restricted diets have been associated with impaired mammary gland development ${ }^{(29,44)}$ leading to impaired milk synthesis ${ }^{(44)}$, and this may also have contributed to reduced offspring growth observed during the suckling period. It is important to note however, that the reduction in protein intake in high fat dams consuming a $36 \%$ fat diet in the current study were more modest (10-25\%) than those typically used in low-protein diet studies $(\sim 50 \%$ reduction $)(45,46,47,48)$.

441 The lower Fasn expression in the liver and adipose tissue of dams exposed to a high- $\underline{36 \%}$ fat 442 diet is consistent with the established role of this enzyme in suppressing lipogenesis in times 443 of energy excess ${ }^{(49)}$. Surprisingly, this change did not appear to be mediated through changes 
in maternal Srebfl mRNA expression, a known regulator of Fasn expression ${ }^{(50)}$. It is important to note that since only mRNA expression was measured, we cannot comment on any differences in protein expression or activity of this transcription factor although mRNA and protein levels have been shown to be closely correlated ${ }^{(23)}$. Following this up at the protein level is a major priority for future study. In the offspring, however, hepatic Fasn expression was not downregulated by exposure to a maternal high- $36 \%$ fat diet but was actually higher in male offspring of dams consuming the $36 \%$ fat compared to the $18 \%$ fat diets at 1 week of age and was accompanied by an increase in $L p l$ expression. In female offspring, however, hepatic Fasn and Sbrepf1 expression at 1 week were influenced by maternal dietary fatty acid ratio, rather than total fat content, with both genes upregulated in offspring of dams fed the low LA diets. In both cases, the upregulation of Sbrefl, Fasn and Lpl genes would be expected to be associated with an upregulation of both lipogenesis and fatty acid uptake. It is worth mentioning that differences in hepatic expression of lipogenic genes in male offspring were consistently associated with maternal dietary fat content whereas differences in female hepatic expression were consistently associated with maternal dietary fatty acid ratio. This suggests that female offspring are more sensitive to changes in the types of maternal dietary fat whereas male offspring are more sensitive to gross maternal fat consumption. Sex specific effects associated with the programming of disease hypothesis have been frequently reported ${ }^{(51)}$. The mechanism by which sex influences these effects, however, remains to be elucidated within a larger perspective, as well as within the context of this study.

We found no evidence that these alterations in hepatic gene expression translated to increases in liver weight, however whether there was any effect on hepatic fat content remains to be determined. In both male and female offspring, relative liver weight was increased in offspring of dams fed the high LA diet. In an aim to further elucidate the source of this increased weight, we measured liver DNA, protein and glycogen composition. Similar to liver weight, glycogen levels were increased in offspring of dams fed the high LA diets. This increase in glycogen, however, was not sufficient enough to completely account for the differences observed in liver weight but may be a contributing factor. Consideration of DNA and protein content of the tissue did not indicate significant changes to cell size or number. More detailed analysis is required to further elucidate the mechanism by which high maternal dietary omega- 6 may impact upon offspring liver morphology and-physiology. 
477 The majority of the hepatic mRNA expression differences, as well as gross differences in liver 478 weight and composition, appeared to be transient and were no longer present at 2 weeks of age. 479 A notable exception was the lower expression of Srebf1 mRNA and higher expression of Pparg 480 in females of dams exposed to a high LA diet compared to the low LA diet, with a similar trend 481 observed in males. Although found in relatively low concentrations in the liver, activation of 482 Pparg has been shown to increase hepatic lipid storage and is elevated in models of hepatic 483 steatosis ${ }^{(52)}$. As such, decreased Pparg expression can alleviate some of the symptoms of 484 hepatic steatosis leading to a reduced liver weight in conjunction with a reduction in hepatic triglyceride content ${ }^{(53)}$. Thus, our finding that female offspring of dams exposed to a high LA diet tended towards to have an increased liver weight at one week of age followed by increased hepatic Pparg expression at two weeks of age may suggest that the increase in Pparg expression is a potential response to the increased liver growth observed a week earlier. Alternatively, parallels may be drawn to the effect of low protein diets where fluctuations between an increased and decreased lipogenic capacity, chiefly mediated by altered Srebfl expression, occur in early life only to settle into a pattern of upregulated lipogenesis at a later life stage ${ }^{(23)}$. Further studies would be needed to directly evaluate this hypothesis.

494 In conclusion, we have demonstrated that exposure to a high- $\underline{36 \%}$ fat diet during gestation and lactation is associated with persistent growth restriction in both male and female offspring irrespective of maternal dietary fatty acid composition. Growth restriction has been associated with a plethora of metabolic disturbances later in life ${ }^{(54,55,56)}$ and transient alterations in gene expression have been suggested as a mechanism for programming changes in metabolic processes within tissues as well as the morphology of the tissues themselves ${ }^{(1)}$. In this study, offspring are still exposed to the experimental diets via the dams milk, and further studies in offspring at older ages are required to assess whether the changes in growth, hepatic gene expression and liver weights in the current study are associated with phenotypic changes that persist once offspring are no longer exposed directly to the altered diet composition. $\underline{\text { In }}$ addition, analysis of lipogenic pathway and adipokines targets at the protein level, as well as whole transcriptome analysis, may yield useful information about their regulation and the extent to which these experimental diets programme other metabolic and regulatory pathways in the liver. Further to thisFinally, the longevity of these perturbations into later life, especially

508 when presented with secondary metabolic challenges such as aging, prolonged high-fat feeding or in the case of female offspring, pregnancy, remains to be elucidated. 


\section{Acknowledgements}

511 The authors gratefully acknowledge the staff at the Bio-Support Unit (University of

512 Nottingham) for help and advice with animal procedures and Zoe Daniel for assistance with

513 molecular analyses.

514

\section{$515 \quad$ Financial Support}

516 BSM is supported by a Career Development Fellowship from the National Health and Medical

517 Research Council of Australia (APP1083009)

518

519 Conflicts of Interest

520 None

521

522 Author Contributions

523 SCL-E, BSM and MJE participated in study design. SAVD carried out the study (assisted by

524 GG), data analysis and preparation of the manuscript which was revised and approved by SCL525 E, BSM, MJE and GG. 


\section{References}

527 1. Langley-Evans SC (2015) Nutrition in early life and the programming of adult disease: a review. J Hum Nutr Diet 28 Suppl 1, 1-14.

2. Ribaroff GA, Wastnedge E, Drake AJ et al. (2017) Animal models of maternal high fat diet exposure and effects on metabolism in offspring: a meta-regression analysis. Obes Rev 18, 673-686.

3. Ainge H, Thompson C, Ozanne SE et al. (2011) A systematic review on animal models of maternal high fat feeding and offspring glycaemic control. Int J Obes (Lond) 35, 325-335. 4. Muhlhausler BS, Ailhaud GP (2013) Omega-6 polyunsaturated fatty acids and the early origins of obesity. Curr Opin Endocrinol Diabetes Obes 20, 56-61. 5. Draycott SAV, Liu G, Daniel ZC et al. (2019) Maternal dietary ratio of linoleic acid to alpha-linolenic acid during pregnancy has sex-specific effects on placental and fetal weights in the rat. Nutrition \& Metabolism 16, 1. 6. Blasbalg TL, Hibbeln JR, Ramsden CE et al. (2011) Changes in consumption of omega-3 and omega- 6 fatty acids in the United States during the 20th century. The American Journal of Clinical Nutrition 93, 950-962.

7. Sioen I, van Lieshout L, Eilander A et al. (2017) Systematic Review on N-3 and N-6 Polyunsaturated Fatty Acid Intake in European Countries in Light of the Current Recommendations - Focus on Specific Population Groups. Ann Nutr Metab 70, 39-50. 8. Ailhaud G, Massiera F, Weill P et al. (2006) Temporal changes in dietary fats: role of n-6 polyunsaturated fatty acids in excessive adipose tissue development and relationship to obesity. Prog Lipid Res 45, 203-236.

9. Tu WC, Cook-Johnson RJ, James MJ et al. (2010) Omega-3 long chain fatty acid synthesis is regulated more by substrate levels than gene expression. Prostaglandins Leukot Essent Fatty Acids 83, 61-68.

10. Gibson RA, Neumann MA, Lien EL et al. (2013) Docosahexaenoic acid synthesis from alpha-linolenic acid is inhibited by diets high in polyunsaturated fatty acids. Prostaglandins Leukot Essent Fatty Acids 88, 139-146.

11. Calder PC (2015) Marine omega-3 fatty acids and inflammatory processes: Effects, mechanisms and clinical relevance. Biochimica et Biophysica Acta (BBA) - Molecular and Cell Biology of Lipids 1851, 469-484. 12. Massiera F, Saint-Marc P, Seydoux J et al. (2003) Arachidonic acid and prostacyclin signaling promote adipose tissue development: a human health concern? J Lipid Res 44, 271 279.

560 13. Massiera F, Barbry P, Guesnet P et al. (2010) A Western-like fat diet is sufficient to induce a gradual enhancement in fat mass over generations. J Lipid Res 51, 2352-2361. 14. Korotkova M, Gabrielsson B, Lonn M et al. (2002) Leptin levels in rat offspring are modified by the ratio of linoleic to alpha-linolenic acid in the maternal diet. J Lipid Res $\mathbf{4 3}$, 1743-1749.

565 15. Much D, Brunner S, Vollhardt C et al. (2013) Effect of dietary intervention to reduce the 566 n-6/n-3 fatty acid ratio on maternal and fetal fatty acid profile and its relation to offspring growth and body composition at 1 year of age. Eur J Clin Nutr 67, 282-288. 16. Muhlhausler BS, Miljkovic D, Fong L et al. (2011) Maternal Omega-3 Supplementation Increases Fat Mass in Male and Female Rat Offspring. Frontiers in Genetics 2, 48. 17. Ibrahim A, Basak S, Ehtesham NZ (2009) Impact of maternal dietary fatty acid composition on glucose and lipid metabolism in male rat offspring aged $105 \mathrm{~d}$. British Journal of Nutrition 102, 233-241. 18. Muhlhausler BS, Gibson RA, Makrides M (2011) The effect of maternal omega-3 longchain polyunsaturated fatty acid (n-3 LCPUFA) supplementation during pregnancy and/or 
575 lactation on body fat mass in the offspring: a systematic review of animal studies.

576 Prostaglandins Leukot Essent Fatty Acids 85, 83-88.

577 19. Gibson RA, Muhlhausler B, Makrides M (2011) Conversion of linoleic acid and alpha-

578 linolenic acid to long-chain polyunsaturated fatty acids (LCPUFAs), with a focus on

579 pregnancy, lactation and the first 2 years of life. Matern Child Nutr 7 Suppl 2, 17-26.

580 20. Lands WEM (2000) Commentary on the Workshop Statement. Prostaglandins,

581 Leukotrienes and Essential Fatty Acids (PLEFA) 63, 125-126.

582 21. SACN (2018) Draft Report: Saturated fats and health.

583 https://www.gov.uk/government/consultations/saturated-fats-and-health-draft-sacn-report

584 (accessed 03/12/2018 2018)

585 22. Liu G, Muhlhausler BS, Gibson RA (2014) A method for long term stabilisation of long

586 chain polyunsaturated fatty acids in dried blood spots and its clinical application.

587 Prostaglandins Leukot Essent Fatty Acids 91, 251-260.

588 23. Erhuma A, Salter AM, Sculley DV et al. (2007) Prenatal exposure to a low-protein diet

589 programs disordered regulation of lipid metabolism in the aging rat. Am J Physiol Endocrinol

$590 \quad$ Metab 292, E1702-1714.

591 24. Rhinn H, Scherman D, Escriou V (2008) One-step quantification of single-stranded DNA in the presence of RNA using Oligreen in a real-time polymerase chain reaction thermocycler. Anal Biochem 372, 116-118.

594 25. Lowry OH, Rosebrough NJ, Farr AL et al. (1951) Protein measurement with the Folin 595 phenol reagent. The Journal of biological chemistry 193, 265-275.

596 26. Blank C, Neumann MA, Makrides M et al. (2002) Optimizing DHA levels in piglets by lowering the linoleic acid to alpha-linolenic acid ratio. J Lipid Res 43, 1537-1543. 27. Brenna JT, Salem N, Sinclair AJ et al. (2009) $\alpha$-Linolenic acid supplementation and conversion to n-3 long-chain polyunsaturated fatty acids in humans. Prostaglandins, Leukotrienes and Essential Fatty Acids 80, 85-91.

28. Tu WC, Muhlhausler BS, Yelland LN et al. (2013) Correlations between blood and tissue omega-3 LCPUFA status following dietary ALA intervention in rats. Prostaglandins Leukot Essent Fatty Acids 88, 53-60.

29. Bautista CJ, Rodriguez-Gonzalez GL, Torres N et al. (2013) Protein restriction in the rat negatively impacts long-chain polyunsaturated fatty acid composition and mammary gland development at the end of gestation. Archives of medical research 44, 429-436. 30. Mercuri O, de Tomas ME, Itarte H (1979) Prenatal protein depletion and Delta9, Delta6 and Delta5 desaturases in the rat. Lipids 14, 822-825.

31. Mantzioris E, James MJ, Gibson RA et al. (1994) Dietary substitution with an alphalinolenic acid-rich vegetable oil increases eicosapentaenoic acid concentrations in tissues. $\mathrm{Am}$ J Clin Nutr 59, 1304-1309.

32. Chan JK, McDonald BE, Gerrard JM et al. (1993) Effect of dietary alpha-linolenic acid and its ratio to linoleic acid on platelet and plasma fatty acids and thrombogenesis. Lipids $\mathbf{2 8}$, 811-817.

33. Mohammad MA, Sunehag AL, Haymond MW (2014) De novo synthesis of milk triglycerides in humans. American journal of physiology Endocrinology and metabolism 306, E838-E847.

34. Hu CC, Qing K, Chen Y (2004) Diet-induced changes in stearoyl-CoA desaturase 1 expression in obesity-prone and -resistant mice. Obesity research 12, 1264-1270.

35. Keesey RE, Hirvonen MD (1997) Body weight set-points: determination and adjustment. J Nutr 127, 1875S-1883S.

36. Khan IY, Taylor PD, Dekou V et al. (2002) Gender-Linked Hypertension in Offspring of Lard-Fed Pregnant Rats. Hypertension 41, 168-175. 

suckling induces cardiovascular dysfunction in adult offspring. Am J Physiol Regul Integr Comp Physiol 288, R127-133. 38. Dyrskog SE, Gregersen S, Hermansen K (2005) High-fat feeding during gestation and nursing period have differential effects on the insulin secretory capacity in offspring from normal Wistar rats. Rev Diabet Stud 2, 136-145. 39. Samuelsson AM, Matthews PA, Argenton M et al. (2008) Diet-induced obesity in female mice leads to offspring hyperphagia, adiposity, hypertension, and insulin resistance: a novel murine model of developmental programming. Hypertension 51, 383-392. 40. Taylor PD, Khan IY, Lakasing L et al. (2003) Uterine artery function in pregnant rats fed a diet supplemented with animal lard. Exp Physiol 88, 389-398.

635 41. Mark PJ, Sisala C, Connor K et al. (2011) A maternal high-fat diet in rat pregnancy reduces growth of the fetus and the placental junctional zone, but not placental labyrinth zone growth. Journal of Developmental Origins of Health and Disease 2, 63-70. 42. Howie GJ, Sloboda DM, Kamal T et al. (2009) Maternal nutritional history predicts obesity in adult offspring independent of postnatal diet. $J$ Physiol 587, 905-915.

640 43. Cerf ME, Muller CJ, Du Toit DF et al. (2006) Hyperglycaemia and reduced glucokinase expression in weanling offspring from dams maintained on a high-fat diet. Br J Nutr 95, 391396.

643 44. Moretto VL, Ballen MO, Goncalves TS et al. (2011) Low-Protein Diet during Lactation and Maternal Metabolism in Rats. ISRN obstetrics and gynecology 2011, 876502.

645

646

647

648

649

650 45. Langley SC, Jackson AA (1994) Increased systolic blood pressure in adult rats induced by fetal exposure to maternal low protein diets. Clinical science (London, England : 1979) 86, 217-222; discussion 121.

46. Langley-Evans SC, Nwagwu M (1998) Impaired growth and increased glucocorticoidsensitive enzyme activities in tissues of rat fetuses exposed to maternal low protein diets. Life Sciences 63, 605-615.

47. Ozanne SE, Martensz ND, Petry CJ et al. (1998) Maternal low protein diet in rats programmes fatty acid desaturase activities in the offspring. Diabetologia 41, 1337-1342. 48. Malandro MS, Beveridge MJ, Kilberg MS et al. (1996) Effect of low-protein diet-induced intrauterine growth retardation on rat placental amino acid transport. The American journal of physiology 271, C295-303.

656 49. Geelen SN, Blazquez C, Geelen MJ et al. (2001) High fat intake lowers hepatic fatty acid synthesis and raises fatty acid oxidation in aerobic muscle in Shetland ponies. Br J Nutr 86, 31-36.

50. Griffin MJ, Sul HS (2004) Insulin regulation of fatty acid synthase gene transcription: roles of USF and SREBP-1c. IUBMB Life 56, 595-600.

661 51. Gabory A, Roseboom TJ, Moore T et al. (2013) Placental contribution to the origins of 662 sexual dimorphism in health and diseases: sex chromosomes and epigenetics. Biology of Sex 663 Differences 4, 5.

664 52. Inoue M, Ohtake T, Motomura W et al. (2005) Increased expression of PPAR $\gamma$ in high fat 665 diet-induced liver steatosis in mice. Biochemical and Biophysical Research Communications 666 336, 215-222.

667 53. Gavrilova O, Haluzik M, Matsusue K et al. (2003) Liver peroxisome proliferator668 activated receptor gamma contributes to hepatic steatosis, triglyceride clearance, and 669 regulation of body fat mass. The Journal of biological chemistry 278, 34268-34276.

670 54. Barker DJ (1995) Fetal origins of coronary heart disease. BMJ 311, 171-174.

671 55. Phillips DI, Barker DJ, Hales CN et al. (1994) Thinness at birth and insulin resistance in adult life. Diabetologia 37, 150-154. 
673 56. Holemans K, Aerts L, Van Assche FA (2003) Fetal growth restriction and consequences 674 for the offspring in animal models. J Soc Gynecol Investig 10, 392-399.

675 
Table 1. Maternal organ weights and gene expression

\begin{tabular}{|c|c|c|c|c|}
\hline & $\begin{array}{c}\text { High LA } \\
\text { (18\% Fat) } \\
\end{array}$ & $\begin{array}{c}\text { High LA } \\
\text { (36\% Fat) } \\
\end{array}$ & $\begin{array}{c}\text { Low LA }(18 \% \\
\text { Fat) } \\
\end{array}$ & $\begin{array}{c}\text { Low LA (36\% } \\
\text { Fat) } \\
\end{array}$ \\
\hline Bodyweight (g) & $308.75 \pm 9.82$ & $288.73 \pm 14.95$ & $303.29 \pm 11.11$ & $302.23 \pm 7.85$ \\
\hline Heart $(\% \mathrm{BW})$ & $0.35 \pm 0.01$ & $0.36 \pm 0.01$ & $0.35 \pm 0.01$ & $0.35 \pm 0.01$ \\
\hline Lungs $(\% \mathrm{BW})^{\mathrm{a}}$ & $0.45 \pm 0.02$ & $0.51 \pm 0.04$ & $0.42 \pm 0.02$ & $0.48 \pm 0.02$ \\
\hline Kidney (\% BW) & $0.78 \pm 0.02$ & $0.83 \pm 0.03$ & $0.82 \pm 0.02$ & $0.79 \pm 0.02$ \\
\hline Liver (\% BW) & $5.01 \pm 0.10$ & $4.80 \pm 0.28$ & $5.28 \pm 0.10$ & $4.88 \pm 0.09$ \\
\hline Brain (\% BW) & $0.59 \pm 0.02$ & $0.59 \pm 0.02$ & $0.58 \pm 0.02$ & $0.59 \pm 0.02$ \\
\hline Gonadal Fat (\% BW) & $1.88 \pm 0.35$ & $2.02 \pm 0.39$ & $1.65 \pm 0.19$ & $1.61 \pm 0.11$ \\
\hline Retroperitoneal Fat (\% BW) & $0.76 \pm 0.13$ & $0.76 \pm 0.13$ & $0.76 \pm 0.08$ & $0.85 \pm 0.15$ \\
\hline \multicolumn{5}{|l|}{ Liver mRNA Expression } \\
\hline Fasn $^{\mathrm{a}^{*}}$ & $20.98 \pm 6.17$ & $7.03 \pm 1.26$ & $25.08 \pm 8.12$ & $9.45 \pm 1.63$ \\
\hline Lpl & $0.20 \pm 0.04$ & $0.19 \pm 0.04$ & $0.19 \pm 0.04$ & $0.13 \pm 0.01$ \\
\hline Pparg & $0.63 \pm 0.22$ & $0.78 \pm 0.18$ & $0.41 \pm 0.09$ & $0.70 \pm 0.16$ \\
\hline Srebf1 & $3.52 \pm 0.91$ & $2.56 \pm 0.64$ & $7.85 \pm 2.57$ & $3.39 \pm 0.61$ \\
\hline \multicolumn{5}{|c|}{ Gonadal Fat mRNA Expression } \\
\hline$F_{a s n^{a^{*}}}$ & $1.29 \pm 0.64$ & $0.18 \pm 0.05$ & $2.50 \pm 1.16$ & $0.37 \pm 0.14$ \\
\hline Lpl & $0.90 \pm 0.23$ & $0.87 \pm 0.06$ & $1.56 \pm 0.41$ & $1.48 \pm 0.46$ \\
\hline Ppparg & $0.91 \pm 0.23$ & $1.22 \pm 0.20$ & $1.12 \pm 0.13$ & $1.16 \pm 0.18$ \\
\hline Srebfl & $1.80 \pm 0.48$ & $1.56 \pm 0.31$ & $3.43 \pm 1.16$ & $2.21 \pm 0.62$ \\
\hline Lep & $0.49 \pm 0.08$ & $1.00 \pm 0.29$ & $1.10 \pm 0.31$ & $1.38 \pm 0.25$ \\
\hline
\end{tabular}

677 All values are mean \pm SEM and $n=6-9$ per dietary group. The effect of dietary fatty acid ratio

678 and dietary fat content were assessed using a two-way ANOVA. a indicates a significant

679 effect of dietary fat content $(\mathrm{P}<0.05, * \mathrm{P}<0.01)$. Although not statistically significant there

680 was some evidence that maternal Srebpf1 expression was influenced by the LA $(\mathrm{P}=0.08)$ and

681 fat content $(\mathrm{P}=0.06)$ of the diet. 
682 Table 2. Birth outcomes

\begin{tabular}{ccccc}
\hline & $\begin{array}{c}\text { High LA } \\
(\mathbf{1 8 \%} \text { Fat) }\end{array}$ & $\begin{array}{c}\text { High LA } \\
(\mathbf{3 6 \%} \text { Fat) }\end{array}$ & $\begin{array}{c}\text { Low LA } \\
(\mathbf{1 8 \%} \text { Fat) }\end{array}$ & $\begin{array}{c}\text { Low LA } \\
(\mathbf{3 6 \%} \text { Fat })\end{array}$ \\
\hline $\mathrm{n}$ & 6 & 8 & 7 & 9 \\
Litter Size & $12.83 \pm 1.19$ & $13.00 \pm 1.21$ & $13.14 \pm 0.40$ & $13.33 \pm 1.08$ \\
Sex Ratio (male/female) & $1.01 \pm 0.23$ & $0.97 \pm 0.24$ & $1.27 \pm 0.28$ & $1.13 \pm 0.26$ \\
Male Birthweight $(\mathrm{g})^{\mathrm{a}}$ & $6.19 \pm 0.53$ & $5.19 \pm 0.18$ & $5.66 \pm 0.14$ & $5.36 \pm 0.11$ \\
Female Birthweight $(\mathrm{g})^{\mathrm{a}}$ & $5.60 \pm 0.37$ & $4.85 \pm 0.21$ & $5.26 \pm 0.14$ & $5.07 \pm 0.12$ \\
\hline
\end{tabular}

683 All values are mean \pm SEM. The effect of dietary fatty acid ratio and dietary fat content was 684 assessed using a two-way ANOVA. ${ }^{\mathrm{a}}$ indicates a significant effect of maternal dietary fat 685 content $(\mathrm{P}<0.05)$. 


\begin{tabular}{|c|c|c|c|c|c|c|c|c|}
\hline \multirow[b]{2}{*}{ Experimental Group } & \multicolumn{4}{|c|}{ Male } & \multicolumn{4}{|c|}{ Female } \\
\hline & $\begin{array}{l}\text { High LA } \\
(18 \% \text { Fat }) \\
\end{array}$ & $\begin{array}{l}\text { High LA } \\
(36 \% \text { Fat })\end{array}$ & $\begin{array}{c}\text { Low LA } \\
(18 \% \text { Fat }) \\
\end{array}$ & $\begin{array}{c}\text { Low LA } \\
(36 \% \text { Fat }) \\
\end{array}$ & $\begin{array}{l}\text { High LA } \\
(18 \% \text { Fat }) \\
\end{array}$ & $\begin{array}{l}\text { High LA } \\
(36 \% \text { Fat })\end{array}$ & $\begin{array}{c}\text { Low LA } \\
(18 \% \text { Fat }) \\
\end{array}$ & $\begin{array}{l}\text { Low LA } \\
(36 \% \text { Fat }) \\
\end{array}$ \\
\hline \multicolumn{9}{|l|}{1 Week Offspring } \\
\hline Bodyweight (g) & $17.52 \pm 1.22^{\mathrm{a}}$ & $12.85 \pm 1.16^{\mathrm{b}}$ & $16.61 \pm 0.41^{\mathrm{a}}$ & $14.20 \pm 0.63^{b}$ & $15.79 \pm 1.11^{\mathrm{a}}$ & $12.44 \pm 1.17^{b}$ & $15.66 \pm 0.66^{\mathrm{a}}$ & $13.40 \pm 0.56^{b}$ \\
\hline Heart (\% BW) & $0.59 \pm 0.07$ & $0.67 \pm 0.06$ & $0.58 \pm 0.04$ & $0.64 \pm 0.02$ & $0.56 \pm 0.02^{\mathrm{a}}$ & $0.70 \pm 0.06^{\mathrm{b}}$ & $0.57 \pm 0.06^{\mathrm{a}}$ & $0.69 \pm 0.04^{\mathrm{b}}$ \\
\hline Lungs (\% BW) & $1.87 \pm 0.05$ & $1.73 \pm 0.04$ & $1.89 \pm 0.05$ & $1.90 \pm 0.06$ & $1.96 \pm 0.11$ & $1.92 \pm 0.05$ & $1.88 \pm 0.12$ & $1.93 \pm 0.05$ \\
\hline Kidney (\%BW) & $1.27 \pm 0.08$ & $1.34 \pm 0.05$ & $1.19 \pm 0.09$ & $1.22 \pm 0.02$ & $1.25 \pm 0.04$ & $1.38 \pm 0.06$ & $1.21 \pm 0.10$ & $1.26 \pm 0.03$ \\
\hline Liver (\% BW) & $3.17 \pm 0.16^{\mathrm{a}}$ & $3.39 \pm 0.13^{\mathrm{a}}$ & $2.81 \pm 0.12^{\mathrm{b}}$ & $2.89 \pm 0.09^{\mathrm{b}}$ & $3.18 \pm 0.10$ & $3.20 \pm 0.27$ & $2.96 \pm 0.13$ & $2.99 \pm 0.05$ \\
\hline Liver Fasn & $0.21 \pm 0.08^{\mathrm{a}}$ & $0.24 \pm 0.05^{b}$ & $0.18 \pm 0.02^{\mathrm{a}}$ & $0.38 \pm 0.04^{b}$ & $0.15 \pm 0.02^{\mathrm{a}}$ & $0.22 \pm 0.03^{a}$ & $0.32 \pm 0.06^{b}$ & $0.35 \pm 0.08^{b}$ \\
\hline Liver $L p l$ & $1.09 \pm 0.38^{\mathrm{a}}$ & $1.26 \pm 0.25^{\mathrm{b}}$ & $0.76 \pm 0.15^{\mathrm{a}}$ & $2.01 \pm 0.38^{\mathrm{b}}$ & $1.26 \pm 0.24$ & $1.37 \pm 0.46$ & $1.59 \pm 0.28$ & $1.81 \pm 0.35$ \\
\hline Liver Pparg & $0.40 \pm 0.16$ & $0.30 \pm 0.07$ & $0.46 \pm 0.14$ & $0.38 \pm 0.08$ & $0.51 \pm 0.11$ & $0.52 \pm 0.13$ & $0.62 \pm 0.16$ & $0.41 \pm 0.06$ \\
\hline Liver Srebpf1 & $0.63 \pm 0.16$ & $0.56 \pm 0.09$ & $0.51 \pm 0.10$ & $0.74 \pm 0.10$ & $0.44 \pm 0.06^{\mathrm{a}}$ & $0.44 \pm 0.05^{\mathrm{a}}$ & $0.64 \pm 0.11^{\mathrm{b}}$ & $0.80 \pm 0.12^{\mathrm{b}}$ \\
\hline \multicolumn{9}{|l|}{2 Week Offspring } \\
\hline Bodyweight (g) & $39.76 \pm 1.67^{\mathrm{a}}$ & $31.78 \pm 2.17^{b}$ & $39.89 \pm 0.59^{\mathrm{a}}$ & $31.56 \pm 1.49^{b}$ & $37.77 \pm 1.55^{\mathrm{a}}$ & $31.70 \pm 2.05^{b}$ & $38.49 \pm 0.93^{\mathrm{a}}$ & $30.75 \pm 1.29^{b}$ \\
\hline Heart (\% BW) & $0.60 \pm 0.01$ & $0.60 \pm 0.02$ & $0.61 \pm 0.03$ & $0.63 \pm 0.01$ & $0.67 \pm 0.06$ & $0.67 \pm 0.01$ & $0.65 \pm 0.03$ & $0.61 \pm 0.02$ \\
\hline Lungs (\% BW) & $1.33 \pm 0.20$ & $1.26 \pm 0.05$ & $1.25 \pm 0.07$ & $1.42 \pm 0.07$ & $1.28 \pm 0.07$ & $1.32 \pm 0.05$ & $1.26 \pm 0.08$ & $1.32 \pm 0.06$ \\
\hline Kidney $(\% \mathrm{BW})$ & $1.05 \pm 0.02$ & $1.02 \pm 0.03$ & $1.06 \pm 0.02$ & $1.00 \pm 0.03$ & $1.17 \pm 0.04$ & $1.15 \pm 0.04$ & $1.14 \pm 0.01$ & $1.05 \pm 0.02$ \\
\hline Gonadal Fat (\%BW) & $0.22 \pm 0.06$ & $0.18 \pm 0.02$ & $0.19 \pm 0.02$ & $0.18 \pm 0.01$ & $0.24 \pm 0.02$ & $0.21 \pm 0.02$ & $0.23 \pm 0.02$ & $0.24 \pm 0.03$ \\
\hline Retroperitoneal Fat (\%BW) & $0.36 \pm 0.01$ & $0.41 \pm 0.04$ & $0.41 \pm 0.02$ & $0.39 \pm 0.02$ & $0.33 \pm 0.03$ & $0.27 \pm 0.02$ & $0.29 \pm 0.03$ & $0.27 \pm 0.01$ \\
\hline Liver $(\%$ BW $)$ & $3.01 \pm 0.06$ & $3.08 \pm 0.14$ & $3.11 \pm 0.02$ & $3.03 \pm 0.02$ & $3.18 \pm 0.09$ & $3.15 \pm 0.09$ & $3.23 \pm 0.05$ & $3.01 \pm 0.10$ \\
\hline Liver FASFasn & $0.17 \pm 0.01$ & $0.18 \pm 0.02$ & $0.19 \pm 0.02$ & $0.20 \pm 0.02$ & $0.19 \pm 0.02$ & $0.20 \pm 0.03$ & $0.22 \pm 0.03$ & $0.24 \pm 0.03$ \\
\hline Liver LPL $\underline{L p l}$ & $1.70 \pm 0.25^{\mathrm{a}}$ & $1.81 \pm 0.29^{\mathrm{b}}$ & $1.60 \pm 0.13^{\mathrm{a}}$ & $2.44 \pm 0.23^{\mathrm{b}}$ & $1.25 \pm 0.16$ & $1.89 \pm 0.16$ & $2.01 \pm 0.29$ & $1.81 \pm 0.08$ \\
\hline Liver PPAR $\underline{\text { Pparg }}$ & $0.56 \pm 0.17$ & $0.66 \pm 0.10$ & $0.48 \pm 0.10$ & $0.42 \pm 0.07$ & $0.79 \pm 0.25^{\mathrm{a}}$ & $0.58 \pm 0.07^{\mathrm{a}}$ & $0.31 \pm 0.06^{\mathrm{b}}$ & $0.43 \pm 0.07^{\mathrm{b}}$ \\
\hline Liver SREBP1eSrebfl & $0.74 \pm 0.02$ & $0.71 \pm 0.08$ & $0.83 \pm 0.06$ & $0.80 \pm 0.05$ & $0.68 \pm 0.07^{\mathrm{a}}$ & $0.68 \pm 0.05^{\mathrm{a}}$ & $0.83 \pm 0.06^{\mathrm{b}}$ & $0.95 \pm 0.10^{\mathrm{b}}$ \\
\hline
\end{tabular}

687 All values are mean \pm SEM. A two-way ANOVA was used to analyse results with maternal dietary fatty acid ratio and maternal dietary fat

688 content as factors. Different superscripts denote values which are significantly different $(\mathrm{P}<0.05) . \mathrm{n}=4-9$ per dietary group. All comparisons are

689 made within sex group. 


\begin{tabular}{|c|c|c|c|c|c|c|c|c|}
\hline \multirow[b]{2}{*}{ Experimental Group } & \multicolumn{4}{|c|}{ Male } & \multicolumn{4}{|c|}{ Female } \\
\hline & $\begin{array}{l}\text { High LA } \\
(18 \% \text { Fat })\end{array}$ & $\begin{array}{l}\text { High LA } \\
(36 \% \text { Fat })\end{array}$ & $\begin{array}{c}\text { Low LA } \\
(18 \% \text { Fat })\end{array}$ & $\begin{array}{c}\text { Low LA } \\
(36 \% \text { Fat })\end{array}$ & $\begin{array}{l}\text { High LA } \\
\text { (18\% Fat) }\end{array}$ & $\begin{array}{l}\text { High LA } \\
\text { (36\% Fat) }\end{array}$ & $\begin{array}{c}\text { Low LA } \\
(18 \% \text { Fat }) \\
\end{array}$ & $\begin{array}{l}\text { Low LA } \\
\text { (36\% Fat) }\end{array}$ \\
\hline \multicolumn{9}{|l|}{1 Week Offspring } \\
\hline $\begin{array}{l}\text { Liver DNA } \\
(\mu \mathrm{g} / \mathrm{mg} \text { tissue })\end{array}$ & $0.48 \pm 0.06$ & $0.54 \pm 0.04$ & $0.56 \pm 0.06$ & $0.52 \pm 0.03$ & $0.51 \pm 0.03$ & $0.51 \pm 0.04$ & $0.50 \pm 0.04$ & $0.52 \pm 0.02$ \\
\hline $\begin{array}{l}\text { Liver Protein } \\
\text { (mg/g tissue) }\end{array}$ & $119.2 \pm 12.8$ & $137.7 \pm 8.9$ & $135.6 \pm 5.2$ & $129.8 \pm 4.9$ & $123.8 \pm 4.5$ & $138.8 \pm 8.3$ & $128.6 \pm 3.3$ & $129.5 \pm 5.2$ \\
\hline $\begin{array}{l}\text { Liver Glycogen } \\
\text { ( } \mu \mathrm{g} / \mathrm{mg} \text { tissue) }\end{array}$ & $12.71 \pm 0.70^{\mathrm{a}}$ & $11.26 \pm 1.86^{\mathrm{a}}$ & $9.72 \pm 1.32^{b}$ & $8.64 \pm 0.76^{\mathrm{b}}$ & $9.70 \pm 0.89$ & $7.73 \pm 0.88$ & $9.00 \pm 1.43$ & $11.27 \pm 1.80$ \\
\hline \multicolumn{9}{|l|}{2 Week Offspring } \\
\hline $\begin{array}{l}\text { Liver DNA ( } \mu \mathrm{g} / \mathrm{mg} \\
\text { tissue) }\end{array}$ & $0.59 \pm 0.03$ & $0.53 \pm 0.05$ & $0.56 \pm 0.04$ & $0.51 \pm 0.03$ & $0.52 \pm 0.02^{\mathrm{a}}$ & $0.61 \pm 0.05^{b}$ & $0.52 \pm 0.03^{\mathrm{a}}$ & $0.57 \pm 0.01^{\mathrm{b}}$ \\
\hline $\begin{array}{l}\text { Liver Protein } \\
\text { (mg/g tissue) }\end{array}$ & $115.1 \pm 3.6$ & $129.9 \pm 13.5$ & $130.2 \pm 10.0$ & $117.9 \pm 9.4$ & $117.2 \pm 9.7$ & $132.3 \pm 9.1$ & $120.7 \pm 9.4$ & $120.6 \pm 6.5$ \\
\hline $\begin{array}{l}\text { Liver Glycogen } \\
\text { ( } \mu \mathrm{g} / \mathrm{mg} \text { tissue) }\end{array}$ & $9.45 \pm 0.61$ & $7.48 \pm 0.54$ & $8.35 \pm 0.98$ & $9.30 \pm 1.75$ & - & - & - & - \\
\hline
\end{tabular}

( $\mu \mathrm{g} / \mathrm{mg}$ tissue) All values are mean \pm SEM. A two-way ANOVA was used to analyse results with maternal dietary fatty acid ratio and maternal dietary fat

692 content as factors. Different superscripts denote values which are significantly different $(\mathrm{P}<0.05)$. $\mathrm{n}=4-9$ per dietary group. All comparisons are 693 made within sex group. 


\section{Figures}

695

696 Figure 1. Maternal average daily (A) feed intake, (B) energy intake and (C) protein intake

697 during pre-feeding, pregnancy and lactation fed on either a high LA (18\% fat) diet (closed

698 circles), high LA (36\% fat) diet (open circles), low LA (18\% fat) diet (closed squares) and a

699 low LA (36\% fat) diet (open squares). Values are means \pm SEM and $n=6-9$ per group. The

700 effects of dietary fatty acid ratio and dietary fat content were determined using a two-way

701 repeated measures ANOVA. * indicates a significant effect of dietary fat content $(* * \mathrm{P}<0.01$,

$702 * * * \mathrm{P}<0.001)$. $\dagger$ indicates a significant interaction between dietary fat content and fatty acid

703 ratio.

704

705 Figure 2. Maternal whole blood fatty acids profile at (A/B) baseline (C/D) after 4 weeks on 706 experimental diet and (D/E) at the end of lactation (3 weeks post-partum). Values are means

$707 \pm$ SEM and $n=6-9$ per group. The effects of dietary fatty acid ratio and dietary fat content

708 were determined using a two-way ANOVA $(* \mathrm{P}<0.05, * * \mathrm{P}<0.01, * * * \mathrm{P}<0.001)$. $\dagger$ indicates a 709 significant interaction effect $(\mathrm{P}<0.05)$.

710

711 Figure 3. Offspring whole blood fatty acids profile at (A/B) one week of age and (C/D) at 712 two weeks of age. Values are means \pm SEM and $n=11-17$ per group. The effects of maternal

713 dietary fatty acid ratio, maternal dietary fat content and sex were determined using a three-

714 way ANOVA. No effect of sex was found for any of the fatty acids measured and so male 715 and female samples were combined for further analysis. * Indicates significant difference $716 \quad(* \mathrm{P}<0.05, * * \mathrm{P}<0.01, * * * \mathrm{P}<0.001) . \dagger$ indicates a significant interaction effect $(\mathrm{P}<0.05)$. 
Figure 1.

A

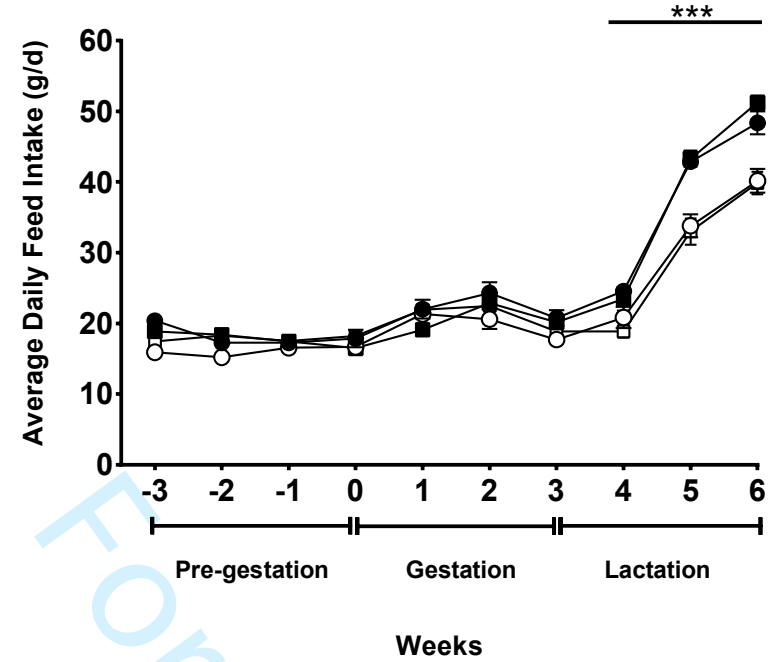

B

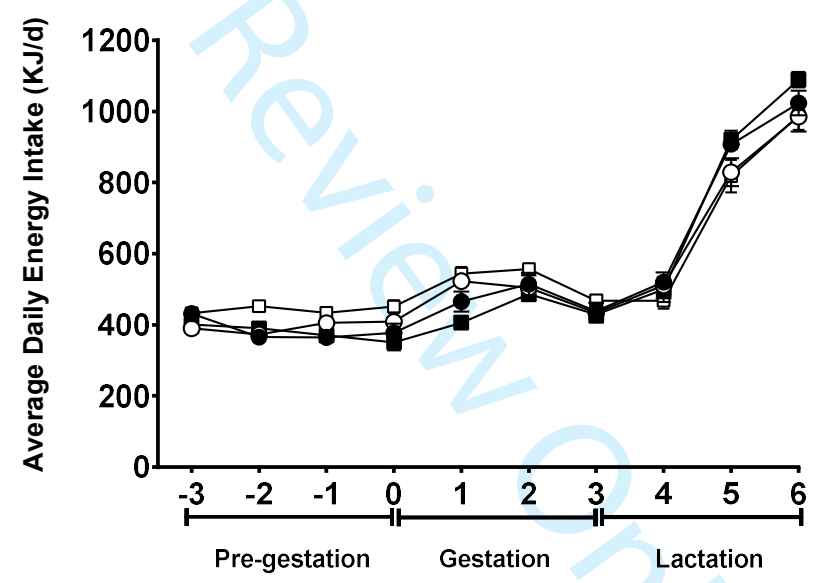

Weeks

C

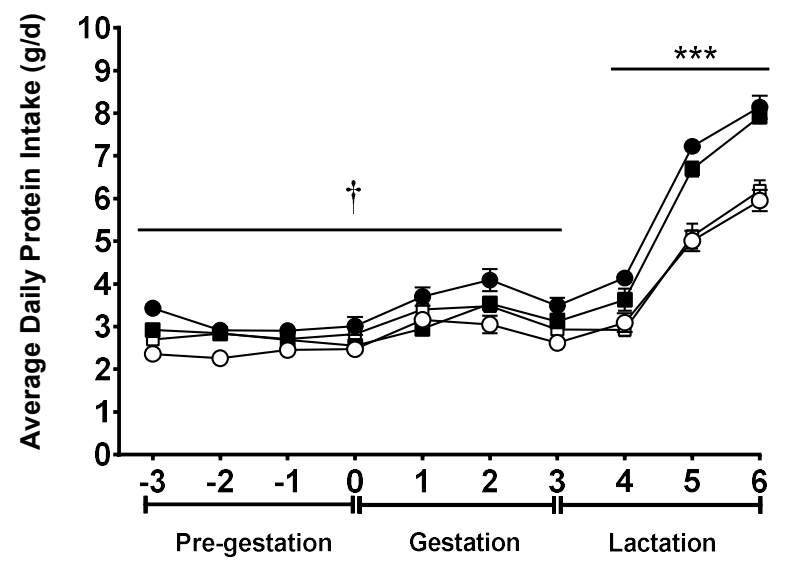

Weeks 
Figure 2.

A

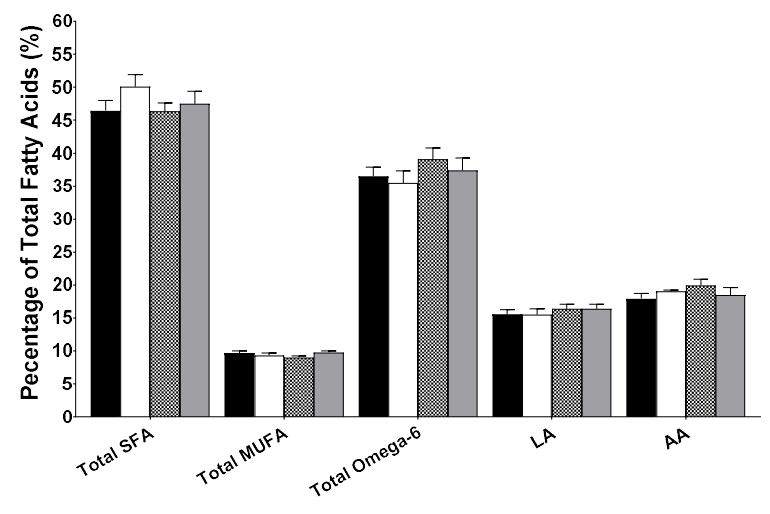

C

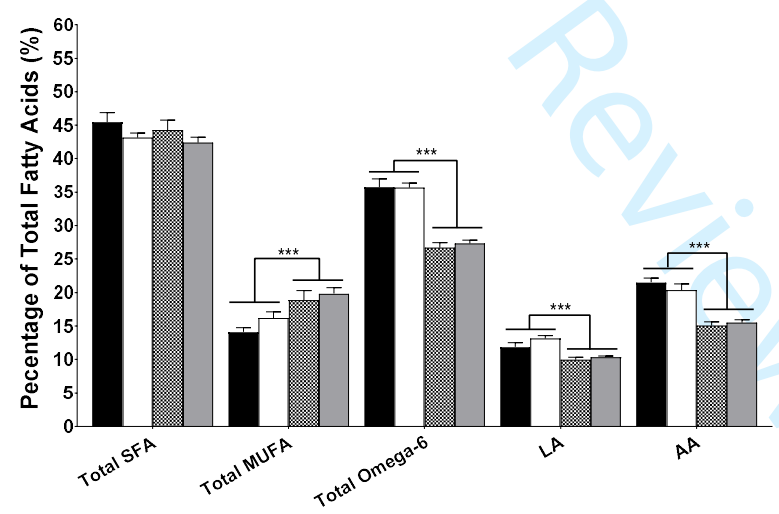

B

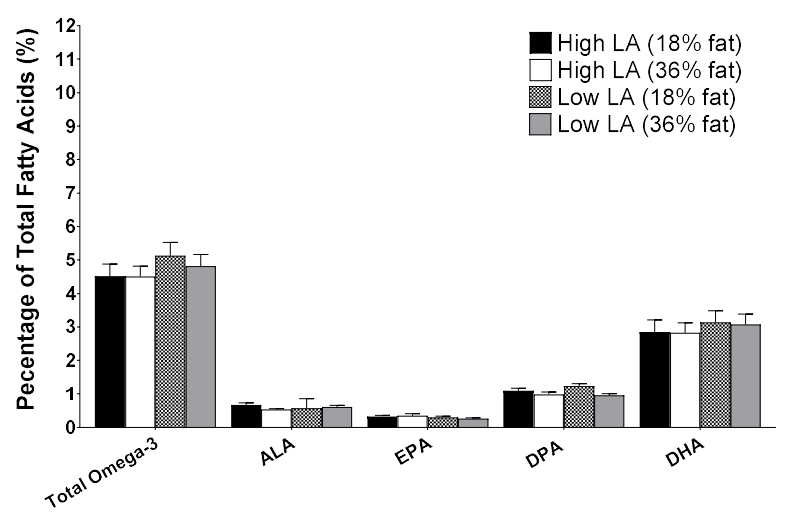

D

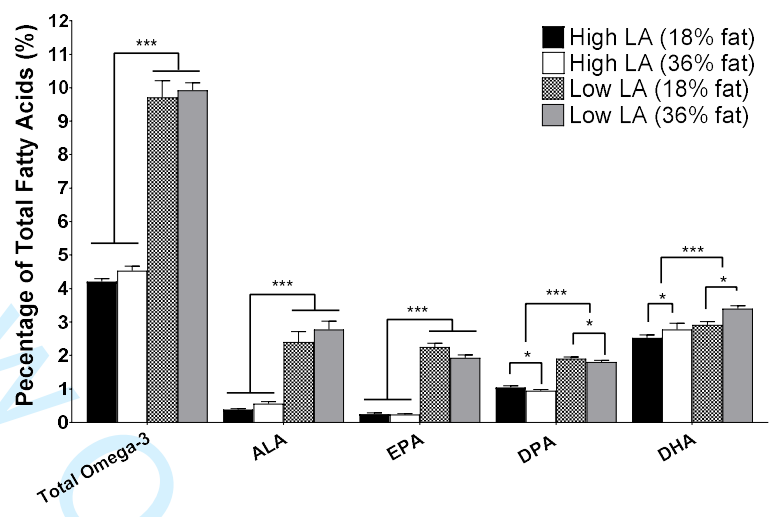

F

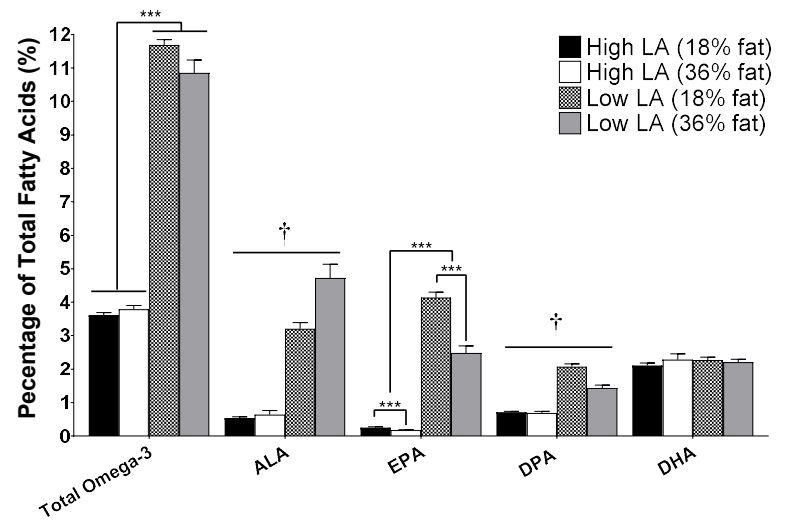




\section{Figure 3.}

A

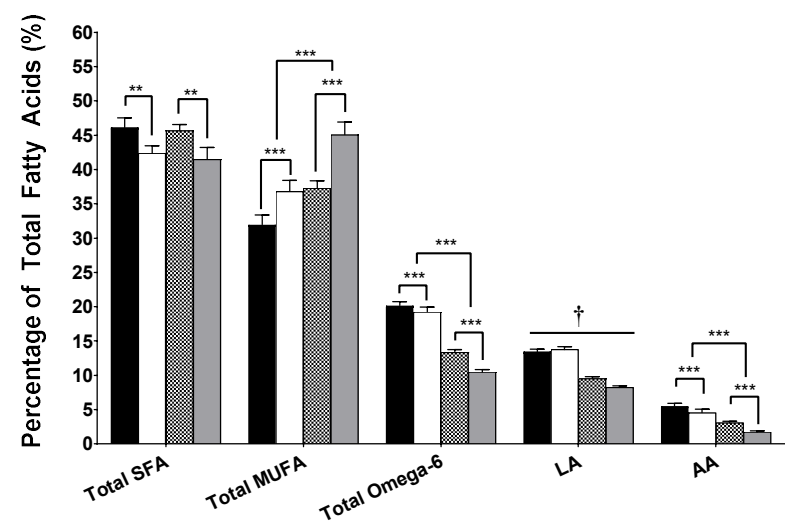

C

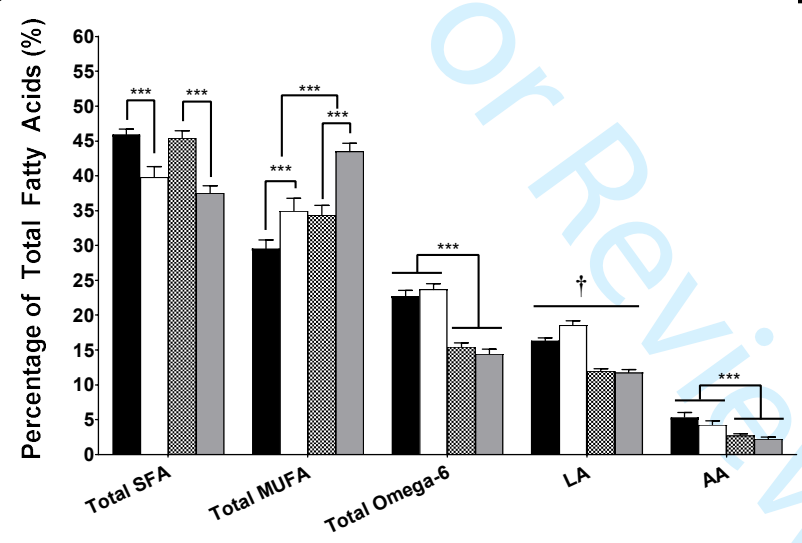

\section{B}

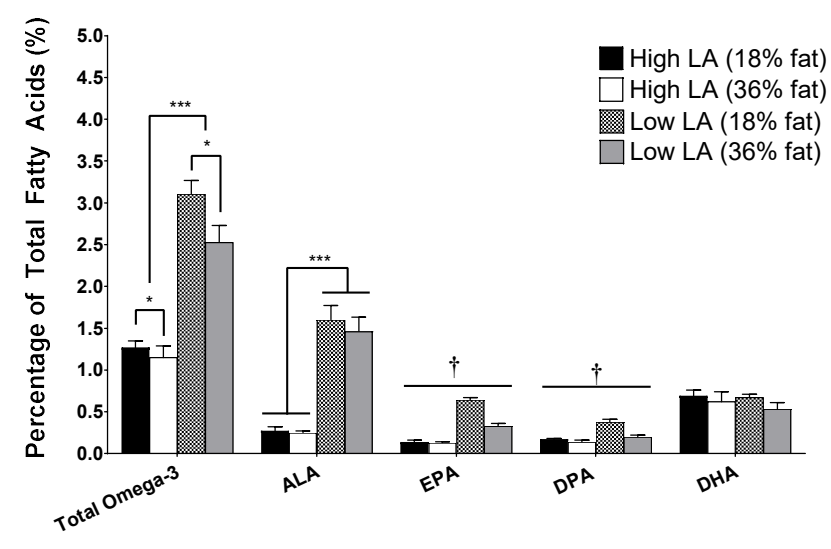

D

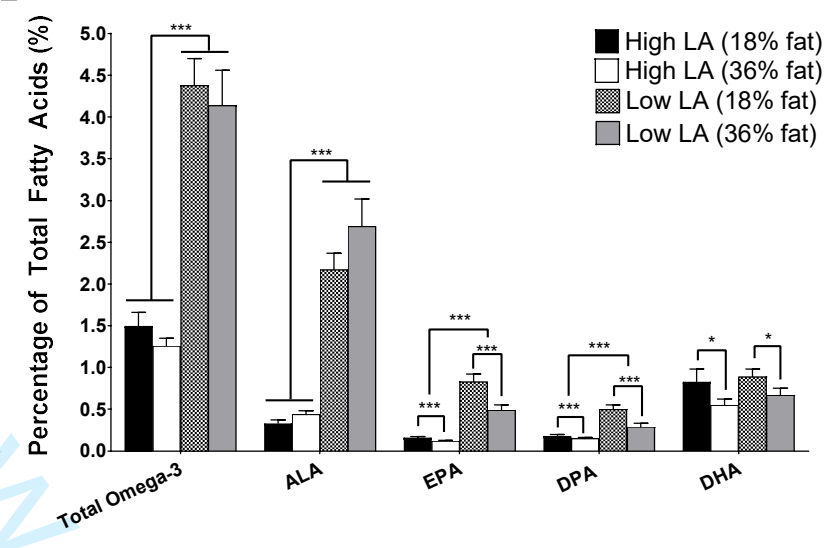




\section{The ARRIVE Guidelines Checklist}

\section{Animal Research: Reporting In Vivo Experiments}

Carol Kilkenny ${ }^{1}$, William J Browne ${ }^{2}$, Innes C Cuthill ${ }^{3}$, Michael Emerson ${ }^{4}$ and Douglas G Altman ${ }^{5}$

${ }^{1}$ The National Centre for the Replacement, Refinement and Reduction of Animals in Research, London, UK, ${ }^{2}$ School of Veterinary Science, University of Bristol, Bristol, UK, ${ }^{3}$ School of Biological Sciences, University of Bristol, Bristol, UK, ${ }^{4}$ National Heart and Lung Institute, Imperial College London, UK, ${ }^{5}$ Centre for Statistics in Medicine, University of Oxford, Oxford, UK.

\begin{tabular}{|c|c|c|c|}
\hline & ITEM & RECOMMENDATION & $\begin{array}{l}\text { Section/ } \\
\text { Paragraph }\end{array}$ \\
\hline Title & 1 & $\begin{array}{l}\text { Provide as accurate and concise a description of the content of the article } \\
\text { as possible. }\end{array}$ & Title \\
\hline Abstract & 2 & $\begin{array}{l}\text { Provide an accurate summary of the background, research objectives, } \\
\text { including details of the species or strain of animal used, key methods, } \\
\text { principal findings and conclusions of the study. }\end{array}$ & Abstract \\
\hline \multicolumn{4}{|l|}{ INTRODUCTION } \\
\hline Background & 3 & $\begin{array}{l}\text { a. Include sufficient scientific background (including relevant references to } \\
\text { previous work) to understand the motivation and context for the study, } \\
\text { and explain the experimental approach and rationale. } \\
\text { b. Explain how and why the animal species and model being used can } \\
\text { address the scientific objectives and, where appropriate, the study's } \\
\text { relevance to human biology. }\end{array}$ & $\begin{array}{l}\text { a. } \\
\text { Introduction } \\
\text { (para. 1-5) } \\
\text { b. } \\
\text { Introduction }\end{array}$ \\
\hline Objectives & 4 & $\begin{array}{l}\text { Clearly describe the primary and any secondary objectives of the study, or } \\
\text { specific hypotheses being tested. }\end{array}$ & $\begin{array}{l}\text { Introduction } \\
\text { Inars } 5 \text { I }\end{array}$ \\
\hline \multicolumn{4}{|l|}{ METHODS } \\
\hline Ethical statement & 5 & $\begin{array}{l}\text { Indicate the nature of the ethical review permissions, relevant licences (e.g. } \\
\text { Animal [Scientific Procedures] Act 1986), and national or institutional } \\
\text { guidelines for the care and use of animals, that cover the research. }\end{array}$ & $\begin{array}{l}\text { Materials and } \\
\text { methods } \\
\text { icnntinn. }\end{array}$ \\
\hline Study design & 6 & $\begin{array}{l}\text { For each experiment, give brief details of the study design including: } \\
\text { a. The number of experimental and control groups. } \\
\text { b. Any steps taken to minimise the effects of subjective bias when } \\
\text { allocating animals to treatment (e.g. randomisation procedure) and when } \\
\text { assessing results (e.g. if done, describe who was blinded and when). } \\
\text { c. The experimental unit (e.g. a single animal, group or cage of animals). } \\
\text { A time-line diagram or flow chart can be useful to illustrate how complex } \\
\text { study designs were carried out. }\end{array}$ & $\begin{array}{l}\text { a. Materials } \\
\text { and methods } \\
\text { (section: } \\
\text { diets) } \\
\text { b. Materials } \\
\text { and methids } \\
\text { c. Materials } \\
\text { and methods } \\
\text { (ser.tinn. }\end{array}$ \\
\hline $\begin{array}{l}\text { Experimental } \\
\text { procedures }\end{array}$ & 7 & $\begin{array}{l}\text { For each experiment and each experimental group, including controls, } \\
\text { provide precise details of all procedures carried out. For example: } \\
\text { a. How (e.g. drug formulation and dose, site and route of administration, } \\
\text { anaesthesia and analgesia used [including monitoring], surgical } \\
\text { procedure, method of euthanasia). Provide details of any specialist } \\
\text { equipment used, including supplier(s). } \\
\text { b. When (e.g. time of day). } \\
\text { c. Where (e.g. home cage, laboratory, water maze). } \\
\text { d. Why (e.g. rationale for choice of specific anaesthetic, route of } \\
\text { administration, drug dose used). }\end{array}$ & $\begin{array}{l}\text { a/b/c/d. } \\
\text { Materials and } \\
\text { methods (all } \\
\text { sections) }\end{array}$ \\
\hline $\begin{array}{l}\text { Experimental } \\
\text { animals }\end{array}$ & 8 & $\begin{array}{l}\text { a. Provide details of the animals used, including species, strain, sex, } \\
\text { developmental stage (e.g. mean or median age plus age range) and } \\
\text { weight (e.g. mean or median weight plus weight range). } \\
\text { b. Provide further relevant information such as the source of animals, } \\
\text { international strain nomenclature, genetic modification status (e.g. } \\
\text { knock-out or transgenic), genotype, health/immune status, drug or test } \\
\text { naïve, previous procedures, etc. }\end{array}$ & $\begin{array}{l}\text { a/b. Materials } \\
\text { and methods } \\
\text { (section: } \\
\text { animals) }\end{array}$ \\
\hline
\end{tabular}




\begin{tabular}{|c|c|c|c|}
\hline $\begin{array}{l}\text { Housing and } \\
\text { husbandry }\end{array}$ & 9 & $\begin{array}{l}\text { Provide details of: } \\
\text { a. Housing (type of facility e.g. specific pathogen free [SPF]; type of cage or } \\
\text { housing; bedding material; number of cage companions; tank shape and } \\
\text { material etc. for fish). } \\
\text { b. Husbandry conditions (e.g. breeding programme, light/dark cycle, } \\
\text { temperature, quality of water etc for fish, type of food, access to food } \\
\text { and water, environmental enrichment). } \\
\text { c. Welfare-related assessments and interventions that were carried out } \\
\text { prior to, during, or after the experiment. }\end{array}$ & $\begin{array}{l}\text { a/b/c. } \\
\text { Materials and } \\
\text { methods } \\
\text { (section: } \\
\text { animals/diets) }\end{array}$ \\
\hline Sample size & 10 & $\begin{array}{l}\text { a. Specify the total number of animals used in each experiment, and the } \\
\text { number of animals in each experimental group. } \\
\text { b. Explain how the number of animals was arrived at. Provide details of any } \\
\text { sample size calculation used. } \\
\text { c. Indicate the number of independent replications of each experiment, if } \\
\text { relevant. }\end{array}$ & $\begin{array}{l}\text { a/b/c. } \\
\text { Materials and } \\
\text { methods } \\
\text { (sections: } \\
\text { Animals/diets/ } \\
\text { statistical }\end{array}$ \\
\hline $\begin{array}{l}\text { Allocating } \\
\text { animals to } \\
\text { experimental } \\
\text { groups }\end{array}$ & 11 & $\begin{array}{l}\text { a. Give full details of how animals were allocated to experimental groups, } \\
\text { including randomisation or matching if done. } \\
\text { b. Describe the order in which the animals in the different experimental } \\
\text { groups were treated and assessed. }\end{array}$ & $\begin{array}{l}\text { a/b. Materials } \\
\text { and methods } \\
\text { (section: } \\
\text { animals) }\end{array}$ \\
\hline $\begin{array}{l}\text { Experimental } \\
\text { outcomes }\end{array}$ & 12 & $\begin{array}{l}\text { Clearly define the primary and secondary experimental outcomes assessed } \\
\text { (e.g. cell death, molecular markers, behavioural changes). }\end{array}$ & $\begin{array}{l}\text { Introduction } \\
\text { Insrs } 5 \text { ) }\end{array}$ \\
\hline $\begin{array}{l}\text { Statistical } \\
\text { methods }\end{array}$ & 13 & $\begin{array}{l}\text { a. Provide details of the statistical methods used for each analysis. } \\
\text { b. Specify the unit of analysis for each dataset (e.g. single animal, group of } \\
\text { animals, single neuron). } \\
\text { c. Describe any methods used to assess whether the data met the } \\
\text { assumptions of the statistical approach. }\end{array}$ & $\begin{array}{l}\text { a/b. Materials } \\
\text { and methods } \\
\text { (section: } \\
\text { Statistical } \\
\text { analvses) }\end{array}$ \\
\hline
\end{tabular}

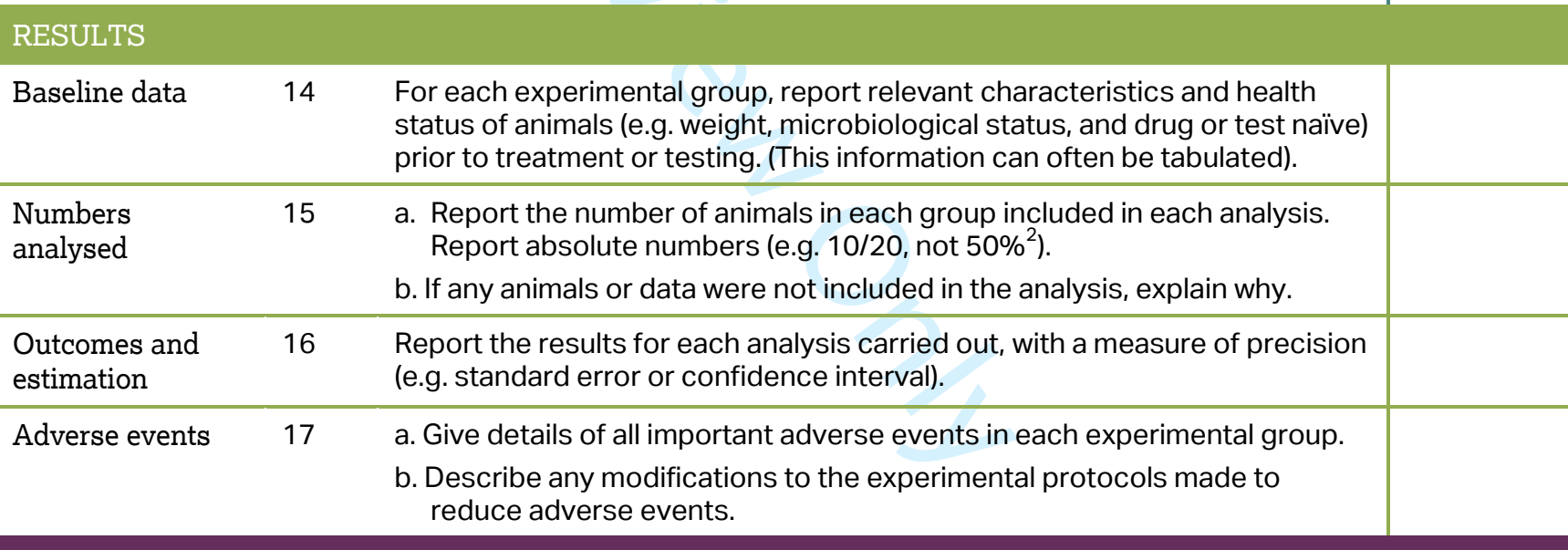

\section{DISCUSSION}

Interpretation/

scientific

implications
18 a. Interpret the results, taking into account the study objectives and
hypotheses, current theory and other relevant studies in the literature.

b. Comment on the study limitations including any potential sources of bias, any limitations of the animal model, and the imprecision associated with the results ${ }^{2}$.

c. Describe any implications of your experimental methods or findings for the replacement, refinement or reduction (the 3Rs) of the use of animals in research.

\begin{tabular}{lcl|l}
\hline $\begin{array}{l}\text { Generalisability/ } \\
\text { translation }\end{array}$ & 19 & $\begin{array}{l}\text { Comment on whether, and how, the findings of this study are likely to } \\
\text { translate to other species or systems, including any relevance to human } \\
\text { biology. }\end{array}$ & Discussion \\
\hline Funding & 20 & $\begin{array}{l}\text { List all funding sources (including grant number) and the role of the } \\
\text { funder(s) in the study. }\end{array}$ & Funding \\
\hline
\end{tabular}

